\title{
Mapping lesion, structural disconnection, and functional disconnection to symptoms in semantic aphasia
}

Nicholas E. Souter ${ }^{\mathrm{a}}$, Xiuyi Wang ${ }^{\mathrm{a}, \mathrm{b}}$, Hannah Thompson ${ }^{\mathrm{c}}$, Katya Krieger-Redwood a , Ajay D. Halai ${ }^{\mathrm{d}}$, Matthew A. Lambon Ralph ${ }^{\mathrm{d}}$, Michel Thiebaut de Schotten e, f, Elizabeth Jefferies ${ }^{\text {a }}$

${ }^{a}$ Department of Psychology, University of York, York, UK

${ }^{\mathrm{b}}$ CAS Key Laboratory of Behavioral Science, Institute of Psychology, Chinese Academy of Sciences, Beijing, China

${ }^{c}$ School of Psychology and Clinical Language Sciences, University of Reading, Reading, UK

${ }^{\mathrm{d}}$ MRC Cognition and Brain Sciences Unit, University of Cambridge, Cambridge, UK

${ }^{\mathrm{e}}$ Brain Connectivity and Behaviour Laboratory, Sorbonne Universities, Paris, France

${ }^{\mathrm{f}}$ Groupe d'Imagerie Neurofonctionnelle, Institut des Maladies

Neurodégénératives-UMR 5293, CNRS, CEA, University of Bordeaux, Bordeaux, France

Corresponding Author: Nicholas E. Souter, University of York, Department of Psychology, York, YO10 5DD

Email:nes522@york.ac.uk

ORCID ID:

Nicholas E. Souter - 0000-0002-0999-1811

Xiuyi Wang - 0000-0002-8197-6229

Hannah Thompson - 0000-0002-0679-1961

Katya Krieger-Redwood - 0000-0003-4143-1168

Ajay D. Halai - 0000-0003-1725-7948

Matthew Lambon Ralph - 0000-0001-5907-2488

Michel Thiebaut de Schotten - 0000-0002-0329-1814

Elizabeth Jefferies - 0000-0002-3826-4330 


\section{Acknowledgements}

We thank Zhiyao Gao for his assistance in the procurement and interpretation of functional network maps, and Lucy Cogdell-Brooke for her guidance in manual lesion tracing. EJ was funded by a European Research Council Consolidator grant (FLEXSEM 771863). MTS was also funded by a European Research Council Consolidator grant (DISCONNECTOME, Grant agreement No. 818521). AH was funded by the Rosetrees Trust (A1699) and European Research Council (GAP: 670428 - BRAIN2MIND_NEUROCOMP to MLR). 


\begin{abstract}
$\underline{\text { Abstract }}$
Patients with semantic aphasia have impaired control of semantic retrieval, often accompanied by executive dysfunction following left hemisphere stroke. Many but not all of these patients have damage to the left inferior frontal gyrus, important for semantic and cognitive control. Yet semantic and cognitive control networks are highly distributed, including posterior as well as anterior components. Accordingly, semantic aphasia might not only reflect local damage but also white matter structural and functional disconnection. Here we characterise the lesions and predicted patterns of structural and functional disconnection in individuals with semantic aphasia and relate these effects to semantic and executive impairment. Impaired semantic cognition was associated with infarction in distributed lefthemisphere regions, including in the left anterior inferior frontal and posterior temporal cortex. Lesions were associated with executive dysfunction within a set of adjacent but distinct left frontoparietal clusters. Performance on executive tasks was also associated with interhemispheric structural disconnection across the corpus callosum. Poor semantic cognition was associated with small left-lateralized structurally disconnected clusters, including in the left posterior temporal cortex. These results demonstrate that while leftlateralized semantic and executive control regions are often damaged together in stroke aphasia, these deficits are associated with distinct patterns of structural disconnection, consistent with the bilateral nature of executive control and the left-lateralized yet distributed semantic control network.
\end{abstract}

\title{
Keywords
}

Stroke, Semantic, Aphasia, Structural, Functional, Disconnection 


\section{Introduction}

To understand the world around us, we draw on two connected but dissociable components; a store of long-term semantic knowledge (e.g., Patterson et al., 2007) and control processes that shape retrieval to suit current circumstances (Lambon Ralph et al., 2017; Rogers et al., 2015). This distinction is highlighted by comparing semantic dementia (SD) and semantic aphasia (SA).

SD patients show conceptual degradation associated with atrophy of the ventral anterior temporal lobes (vATL) and highly consistent semantic deficits across tasks that probe the same items (Bozeat et al., 2000; Mummery et al., 2000), in line with the view this site acts as a 'semantic hub' for heteromodal concepts (Lambon Ralph et al., 2017; Patterson et al., 2007). According to the hub-and-spoke model of semantic cognition, the vATL 'hub' works in concert with modality-specific 'spokes' in order to generate generalisable and coherent representations (Rogers et al., 2021). In contrast to those with SD, patients with semantic aphasia (SA) have intact conceptual representations but an impaired ability to retrieve information in a flexible and context-appropriate manner, following left inferior frontal and/or temporoparietal stroke (Jefferies, 2013; Jefferies \& Lambon Ralph, 2006) ${ }^{1}$. Such deficits are multi-modal, such that these patients experience impairments in non-verbal tasks such as matching pictures based on appropriate object use (Corbett et al., 2011), as well as on verbal tasks requiring semantic matching between words (Noonan et al., 2010). SA patients show stronger-than-normal effects of cues and miscues designed to help or hinder relevant conceptual retrieval (Jefferies et al., 2008; Lanzoni et al., 2019; Noonan et al., 2010). These effects are accompanied by poor retrieval of weak associations and the subordinate meanings of ambiguous words and objects, as well as more significant impairment when targets are presented alongside strong distractors (Noonan et al., 2010). Consequently, the study of these patients can provide insights into the neurocognitive mechanisms that allow us to use our conceptual knowledge in a controlled way that is appropriate to the context.

Semantic deficits in SA are thought to reflect damage to a distributed but largely leftlateralised semantic control network (SCN), but evidence demonstrating the functional relevance of connectivity between key nodes of the SCN is still lacking. While the peak

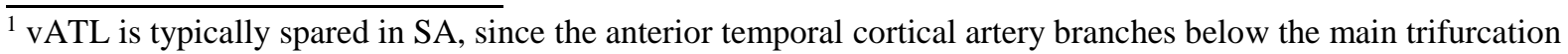
of the middle cerebral artery and because this watershed region has a dual blood supply from the middle and posterior cerebral arteries (Borden, 2006; Conn, 2003).
} 
bioRxiv preprint doi: https://doi.org/10.1101/2021.12.01.470605; this version posted December 2, 2021. The copyright holder for this preprint (which was not certified by peer review) is the author/funder, who has granted bioRxiv a license to display the preprint in perpetuity. It is made available under aCC-BY-NC-ND 4.0 International license.

lesion overlap in SA is in the left posterior inferior frontal gyrus (IFG), not every SA case shows damage to the IFG. Lesions are also highly variable within the left parietal and posterior temporal cortex (Chapman et al., 2020; Hallam et al., 2018; Lanzoni et al., 2019; Stampacchia et al., 2018). This lesion heterogeneity is anticipated by neuroimaging metaanalyses of healthy participants (Jackson, 2021; Noonan et al., 2013), which highlight reliable activation of posterior components of the $\mathrm{SCN}$, most notably the left posterior middle temporal gyrus (pMTG), along with the IFG in tasks with high semantic control demands (e.g., Becker et al., 2020; Krieger-Redwood et al., 2015; Zhang et al., 2021). Studies employing inhibitory stimulation suggest that both the left IFG and pMTG play a critical role in semantic control in healthy participants (Whitney et al., 2011; Davey et al., 2015). Moreover, damage or inhibitory stimulation of the left IFG elicits increased activation in the left pMTG (Hallam et al., 2018; 2016), as would be expected within a distributed functional network. While this work suggests that both anterior and posterior sites support semantic control, the structural and functional disconnection that is anticipated from the diverse lesions in SA has not been clearly delineated. We might expect similar and overlapping disconnection patterns across cases with different lesions (affecting anterior and posterior components of the SCN, for example), given the same network is thought to be damaged in patients with semantic deficits.

Another unresolved issue concerns the extent to which the SCN is distinct from the multiple-demand network (MDN), which supports executive control across domains (Fedorenko et al., 2013). Like the SCN, the MDN is highly distributed with both anterior and posterior components. Neuroimaging studies of healthy participants suggest these networks are adjacent in multiple regions of the cortex, with nodes of the SCN falling in between the MDN and regions of the default-mode network (DMN) in the left hemisphere (Wang et al., 2020; Davey et al., 2016; Gao et al., 2021). Posterior aspects of the left IFG bordering the inferior frontal sulcus are implicated in domain-general aspects of control. Anterior aspects of the left IFG that fall within the DMN are thought to be engaged more specifically in controlled semantic retrieval (Badre \& Wagner, 2007; Krieger-Redwood et al., 2015; Zhang et al., 2021). This spatial proximity of the SCN and MDN in the left hemisphere may explain why SA patients frequently present with impairments in non-semantic executive tasks (Thompson et al., 2018). Since MDN regions support the performance of semantic tasks with high control demands (Krieger-Redwood et al., 2015; Wang et al., 2020), damage to the MDN will contribute to the profile of semantic impairment in SA. Nevertheless, the SCN and 
bioRxiv preprint doi: https://doi.org/10.1101/2021.12.01.470605; this version posted December 2, 2021. The copyright holder for this preprint (which was not certified by peer review) is the author/funder, who has granted bioRxiv a license to display the preprint in perpetuity. It is made available under aCC-BY-NC-ND 4.0 International license.

MDN diverge in their degrees of lateralisation. While the SCN is largely left-lateralised, the MDN comprises distributed bilateral regions (Camilleri et al., 2018; Gao et al., 2021;

Gonzalez Alam et al., 2019). As such, effective semantic control should involve connectivity within the left-hemisphere, while domain-general control should rely more on interhemispheric connectivity (Gonzalez Alam et al., 2021), allowing the integration of information across right-hemisphere regions dominant in the control of visuospatial processing with contralateral frontal regions (Wu et al., 2016).

Given that the SCN and MDN have similar topographical organisation in the left hemisphere but distinct lateralisation patterns, we might expect semantic and executive deficits in SA following left-hemisphere stroke to be associated with similar lesion profiles and yet distinct patterns of disconnection. Structural and functional disconnection within the left-lateralised components of the SCN may underpin semantic deficits in SA. At the same time, broader executive impairment across domains may relate to a disconnection between control regions in the left and right hemispheres. Studies already show that white matter connections between anterior temporal and occipital/middle temporal regions predict semantic impairment beyond the contribution of grey matter damage alone (Fang et al., 2018). Tracts implicated in semantic cognition in the left hemisphere include the inferior fronto-occipital fasciculus (IFOF), anterior thalamic radiation (ATR), uncinate fasciculus (UF) and inferior longitudinal fasciculus (ILF; Almairac et al., 2015; Han et al., 2013; Sierpowska et al., 2019). Studies with neurologically healthy adults that specifically investigated tracts associated with semantic control have similarly implicated left ILF (Marino et al., 2020) and left IFOF (Nugiel et al., 2016). Moreover, distinct changes in structural connectivity are associated with semantic impairment in SD and SA patients: SA is related to changes in left frontal-subcortical and left frontal-temporal/occipital networks, while symptoms in SD are associated with fractional anisotropy of a left medial temporal white matter network (Ding et al., 2020). Conversely, a decline in executive function occurs with compromised integrity of the corpus callosum, in both healthy ageing (Johnson et al., 2017; Jokinen et al., 2007; Voineskos et al., 2012) and patient groups (Bodini et al., 2013), consistent with the theory that performance in complex and demanding tasks relies on crosshemispheric integration (Gazzaniga, 2005; Schulte \& Müller-Oehring, 2010). Accordingly, impairments in semantic control and executive function may be predicted by left-lateralised and bilateral disconnection, respectively. 
bioRxiv preprint doi: https://doi.org/10.1101/2021.12 01.470605; this version posted December 2, 2021. The copyright holder for this preprint (which was not certified by peer review) is the author/funder, who has granted bioRxiv a license to display the preprint in perpetuity. It is made available under aCC-BY-NC-ND 4.0 International license.

This study aimed to characterise typical patterns of infarct, plus structural and functional disconnection, in a sample of $23 \mathrm{SA}$ patients. We assessed the impact of lesion location in SA on functional networks, including the SCN, MDN and DMN, given all these networks are implicated in semantic cognition. Individual patterns of structural disconnection were predicted by tracking white matter fibres likely to pass through a patient's lesion based on diffusion-weighted imaging data from neurologically healthy participants (Foulon et al., 2018). Structural disconnection in stroke patients assessed in this way has been shown to reflect functional activation better than lesion location alone (Thiebaut de Schotten et al., 2020), and to predict several post-stroke symptoms including apraxia (Garcea et al., 2020) and impaired executive function (Langen et al., 2018). Similarly, measures of functional disconnection were derived by assessing patterns of intrinsic functional connectivity with the lesion site, using resting-state scans from neurologically healthy participants (Salvalaggio et al., 2020). The use of such 'connectomic' data may serve as a practical approach in better elucidating the relationship between diffuse networks and impairments following cerebral insult (Fornito et al., 2015).

We explored associations between measures of lesion location, structural disconnection, and functional disconnection and performance on semantic cognition and nonsemantic executive function tests. We would expect adjacent or similar lesions to predict deficits of semantic cognition and executive control, given that the networks supporting these functions in the left hemisphere are thought to have a similar topological organisation. Moreover, we would expect peak lesion location to fall within the SCN, given that SA patients show deregulated conceptual retrieval. Given their spatial proximity, we may also predict some lesion extension into adjacent DMN, MDN, and core semantic regions. These lesions should be accompanied by widespread structural and functional disconnection that is again maximal within the SCN. However, since executive control is thought to draw on the bilateral MDN, while semantic control is strongly left-lateralised, the broader patterns of disconnection that predict performance within these domains may be more clearly distinct. Accordingly, poor semantic cognition should be associated with left-lateralised patterns of structural and functional disconnection (across left-hemisphere components of DMN, SCN and MDN). Executive dysfunction on non-semantic tasks might be related to more bilateral patterns of disconnection specifically within MDN. 


\section{Method}

\subsection{Participants}

Participants were 23 SA patients with impaired multimodal semantic control following left hemisphere stroke. Patients were recruited from communication support groups across Yorkshire, Surrey, and Manchester in the UK. Patients were all right-handed and native English speakers, had a mean age of $62.2(\mathrm{SD}=11.9)$, a mean age of leaving education of $16.3(\mathrm{SD}=1.5)^{2}$, and a mean of 6.7 years $(\mathrm{SD}=5.5)$ since their most recent stroke. Patients were selected to show impairment on at least one verbal and one nonverbal measure of semantic control, in line with Head's (1926) definition of SA as multimodal impairment in the manipulation of knowledge for symbolic processing.

\subsection{Background neuropsychological testing}

Patients completed a series of tests probing language, memory, executive function, visuospatial processing, and semantic cognition. Patients' individual performance on tests of background neuropsychology and semantic cognition can be seen in Supplementary Table 1 and Supplementary Table 2, respectively. Patients had variable impairment of word repetition and commonly showed impaired category fluency, letter fluency and verbal working memory. Fourteen patients were impaired on at least one test of executive function. Most patients had relatively good visuospatial processing. A description of these tasks and performance is provided in Supplementary Materials (Background Neuropsychology).

All patients were impaired on at least one verbal and one nonverbal measure of semantic cognition, in line with our inclusion criteria. We found $78 \%$ of patients were impaired on the word version of Camel and Cactus Test (CCT) of semantic associations, while $52 \%$ were impaired on the picture version. Most patients showed near-ceiling performance on a simple test of word-picture matching, as has previously been shown (e.g., Lanzoni et al., 2019; Thompson et al., 2018). The majority of cases (80\%) showed impaired picture naming. All patients who were tested with phonemic cueing showed evidence of improved accuracy as a result, except for patients performing at floor level. Similarly, when the relevant data was available, patients showed strong effects of semantic control manipulations across a series of assessments, including difficulty retrieving subordinate conceptual information, susceptibility to contextual cues and miscues, and deleterious effects of semantic distractors on synonym judgement.

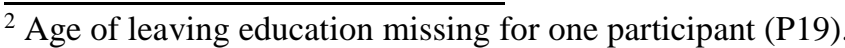


Principal components analysis (PCA) with oblique rotation was used to extract a composite score for semantic tasks that were maximally available across the sample: namely word and picture CCT, and overall performance on the no cue version of the 'ambiguity' assessment (Noonan et al., 2010). In doing so, we aimed to obtain a single score to reflect semantic performance across tasks for each participant. PCA was performed with data from the 21 patients who completed all three tests. This analysis revealed that all three tests loaded strongly on a single component with an eigenvalue of 2.6 (loadings: CCT words $=.95$; CCT pictures $=.92$; ambiguity $=.92$ ) that explained $87 \%$ of variance in performance. We extracted a 'semantic cognition composite score' from this component, with lower values reflecting greater impairment of semantic cognition. Patients' individual composite scores are presented in Supplementary Table 2. Performance on the Brixton Spatial Anticipation Test (Burgess \& Shallice, 1997) was taken to reflect patients' degree of impairment in cognitive control beyond the semantic domain ${ }^{3}$, for the 20 patients for whom data were available. This task involved anticipating the locations where a dot would move to, given past patterns, and shifting these predictions when the pattern changed. Performance on the Brixton test correlated positively with patients' semantic composite scores $(r(18)=.61, p=.005)$, providing evidence that poorer semantic performance was accompanied by poorer executive control on a non-verbal task.

\subsection{MRI acquisition}

Structural T1 images were obtained for all patients. Patients in York $(\mathrm{N}=13)$ were scanned using a 3T GE HDx Excite MRI scanner on a T1-weighted 3D fast spoiled gradient echo sequence $\left(\mathrm{TR}=7.8 \mathrm{~ms}, \mathrm{TE}=\right.$ minimum full, flip-angle $=20^{\circ}$, matrix size $=256 \times 256$, 176 slices, voxel size $=1.13 \times 1.13 \times 1 \mathrm{~mm})$. Patients in Manchester $(\mathrm{N}=8)$ were scanned using a 3T Philips Achieva MRI scanner using a T1-weighted 3D inversion recovery sequence $\left(\mathrm{TR}=9.0 \mathrm{~ms}, \mathrm{TE}=3.93 \mathrm{~ms}\right.$, flip-angle $=8^{\circ}$, matrix size $=256 \times 256,150$ slices, voxel size $=1 \times 1 \times 1 \mathrm{~mm})$. Scanning parameters for patients scanned in Surrey $(\mathrm{N}=2)$ are not available. For analysis of functional disconnection, we used resting state scans from an independent sample of 141 neurologically healthy participants from the Nathan-Kline Institute / Rockland Sample publicly available dataset, collected on a Siemens Magnetom TrioTim syngo scanner $\left(\mathrm{TR}=2,500 \mathrm{~ms}, \mathrm{TE}=30 \mathrm{~ms}\right.$, flip-angle $=80^{\circ}$, matrix size $=256 \times 256$

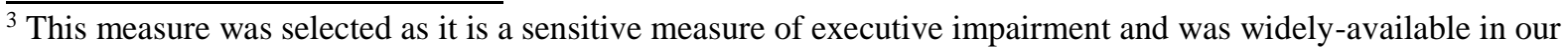
sample.
} 
x 200, 38 slices, voxel size $=3 \times 3 \times 3 \mathrm{~mm}$, slice thickness $=3 \mathrm{~mm})^{4}$. Estimates of structural disconnection were based on diffusion-weighted data from healthy controls, collected on a 3T GE Signa HDx TwinSpeed system $(\mathrm{TR}=20 / 30 \mathrm{R}-\mathrm{R}$ intervals, $\mathrm{TE}=93.4 \mathrm{~ms}$, matrix size $=$ $128 \times 128,60$ slices, voxel size $=2.4 \times 2.4 \times 2.4 \mathrm{~mm}$ ).

\subsection{Lesion segmentation}

Patients' T1 scans underwent brain extraction in ANTs using a template from the OASIS Brain Project (https://www.oasis-brains.org/; Marcus et al., 2010). Registration to MNI152 space was also performed using ANTs linear registration (version 2.1.0; Avants et al., 2011; 2014), which utilises a symmetric normalisation model. Default parameters were used including aligning centres and orientations, accounting for scaling factors, ending with affine transformation, and including optimisation for cost function (Avants et al., 2011). Patients' lesions were then manually drawn in MRICron, using a combination of the 3D fill tool feature and subsequent validation of each slice. Care was taken to avoid implicating enlarged sulci or ventricles in the lesion: cases where sulci or ventricles have been implicated by the 3D tool are typically observable through visual inspection by cross-referencing axial, sagittal, and coronal views of a given slice, and in such cases the respective highlighting was removed from the lesion drawing.

\subsection{Structural disconnection}

The BCBtoolkit (Foulon et al. 2018; http://www.toolkit.bcblab.com) was used to generate probabilistic maps of spreading structural disconnection. This approach uses a set of ten healthy controls' DWI datasets (Rojkova et al., 2016) to track fibers passing through each patient's lesion. This makes it possible to estimate likely structural disconnection from a lesion even when no diffusion-weighted imaging is acquired. Patients' lesions in the MNI152 are used as seeds for tractography in Trackvis (Wang et al., 2007). Tractographies from the lesions were transformed in visitation maps (Thiebaut de Schotten et al., 2011) and binarised. Finally, a percentage overlap map was produced by summing the normalized visitation map of each healthy subject at each point in MNI space. In the resulting disconnectome map for each patient, the value of each voxel reflects the interindividual variability of tract reconstructions in controls, resulting in a value between 0 and 1 reflecting the probability of disconnection (Thiebaut de Schotten et al., 2015). Disconnectome maps for each patient were

\footnotetext{
${ }^{4}$ See (http://fcon_1000.projects.nitrc.org/indi/pro/nki.html) for further details on this dataset, and (http://fcon_1000.projects.nitrc.org/indi/pro/nki/NKI_R_FMRI_PROTOCOL.pdf) for full scanning parameters.
} 
bioRxiv preprint doi: https://doi.org/10.1101/2021.12 01.470605; this version posted December 2, 2021. The copyright holder for this preprint (which was not certified by peer review) is the author/funder, who has granted bioRxiv a license to display the preprint in perpetuity. It is made available under aCC-BY-NC-ND 4.0 International license.

thresholded at 0.5 , such that the disconnectome maps correspond to the exact white matter anatomy of more than $50 \%$ of the healthy controls (Foulon et al., 2018).

In order to assess the effect of structural disconnection on specific white matter tracts, probabilistic tracts included in the BCBtoolkit (Foulon et al., 2018) were extracted, thresholded at a value of 0.95 , and used to visualise the tracts of interest. We were specifically interested in tracts implicated in semantic cognition, language, domain-general cognitive control, or the confluence of these functions (Agosta et al., 2010; Almairac et al., 2015; Bodini et al., 213; Dick et al., 2019; Ding et al., 2020; Han et al., 2013; Huang et al., 2015; Johnson et al., 2017; Marino et al., 2020; Nugiel et al., 2016; Rizio \& Diaz, 2016; Sierpowska et al., 2019; Spitz et al., 2013), including the uncinate fasciculus (UF), anterior thalamic radiation (ATR), inferior longitudinal fasciculus (ILF), inferior front occipitalfasciculus (IFOF), frontal aslant tract (FAT), arcuate fasciculus (AF), superior longitudinal fasciculus (SLF), and corpus callosum. We quantitatively assessed the effect of structural disconnection on these tracts using the Tractotron function of the BCBtoolkit (Foulon et al., 2018). Tractotron maps the lesion from each patient onto tractography reconstructions of specific white matter pathways obtained from a group of healthy controls (Rojkova et al., 2016), and quantifies both the probability of a given tract being disconnected, and the proportion of this tract that is likely to be disconnected (Thiebaut de Schotten et al. 2014).

\subsection{Functional disconnection}

We generated maps of functional connectivity to each patient's lesion location, to provide an indirect measure of functional disconnection. For this purpose, we used the CONN functional connectivity toolbox V.20.b (Whitfield-Gabrieli \& Nieto-Castanon, 2012; www.nitrc.org/projects/conn) in MATLAB. Each patients' lesion was used to generate seedbased connectivity maps, which present the degree of functional connectivity between a given seed and every voxel in the brain. Lesion seeds were analysed relative to an independent sample of resting-state fMRI scans from neurologically healthy participants (as described in Section 2.3).

Functional resting-state volumes were skull-stripped, slice-time (interleaved) and motion-corrected, and co-registered to the high-resolution structural image, spatially normalised to MNI space using the unified-segmentation algorithm, smoothed with a $6 \mathrm{~mm}$ FWHM Gaussian kernel, and band-passed filtered (.008-.09 Hz) to reduce low-frequency drift and noise effects. A pre-processing pipeline of nuisance regression included motion 
bioRxiv preprint doi: https://doi.org/10.1101/2021.12.01.470605; this version posted December 2, 2021. The copyright holder for this preprint (which was not certified by peer review) is the author/funder, who has granted bioRxiv a license to display the preprint in perpetuity. It is made available under aCC-BY-NC-ND 4.0 International license.

(twelve parameters: the six translation and rotation parameters and their temporal derivatives) and scrubbing (all outlier volumes were identified through the artifact detection algorithm included in CONN, with conservative settings: scans for each participant were flagged as outliers based on scan-by-scan change in global signal above $\mathrm{z}>3$, subject motion threshold above $5 \mathrm{~mm}$, differential motion and composite motion exceeding $95 \%$ percentile in the normative sample). We used the anatomical CompCor approach to remove these nuisance variables in a single linear regression step in order to provide a clear signal (Behzadi et al., 2007), as well as a linear detrending term, eliminating the need for global signal normalisation. Group-level analyses in CONN were cluster-size FWE corrected and controlled for the number of seeds (Bonferroni, $\mathrm{p}<.002$ ), and used a height threshold of $\mathrm{p}<$ .001 . The resulting output files were thresholded such that only positively associated voxels remained and were taken to reflect patients' maps of functional disconnection.

\subsection{Functional networks}

We assessed the effect of patients' lesions on networks of interest. To identify the SCN, we used the map from Jackson (2021), derived from a meta-analysis of studies that manipulated semantic control demands. To identify semantic regions outside the SCN, we used a map from the meta-analytic tool Neurosynth (Yarkoni et al., 2011) for the term 'Semantic'. The MDN was defined using a map from Fedorenko et al. (2013) reflecting activation associated with global effects of difficulty across seven diverse tasks, thresholded at $\mathrm{t}>1.5$. We also identified areas common to both the SCN and MDN, using a conjunction of the respective maps described above. Finally, the DMN was defined using the 7-network parcellation from Yeo et al. (2011). All maps were mutually exclusive such that (1) any voxels contained within the MDN, SCN, or Neurosynth semantic network were removed from the DMN (i.e. this map focussed on domain-general responses, excluding regions specifically implicated in semantic cognition); (2) any voxels contained within the SCN or MDN were removed from the Neurosynth semantic network (i.e., this map excluded both DMN and control regions and as such focussed on those involved in semantic representation or more automatic aspects of retrieval and not more controlled patterns of retrieval); and (3) any voxels contained within both the SCN and MDN were removed from each individual map and placed in the conjunctive ' $\mathrm{MDN}+\mathrm{SCN}$ ' map (such that the $\mathrm{SCN}$-only regions were not implicated in domain-general control).

We assessed the mean percentage of each network that was lesioned across the sample. As all lesions were restricted to the left hemisphere, each network was confined to 
bioRxiv preprint doi: https://doi.org/10.1101/2021.12.01.470605; this version posted December 2, 2021. The copyright holder for this preprint (which was not certified by peer review) is the author/funder, who has granted bioRxiv a license to display the preprint in perpetuity. It is made available under aCC-BY-NC-ND 4.0 International license.

the left hemisphere for this analysis. All network maps were binarized prior to analysis. We identified for a given patient, the number of voxels implicated in both their binary lesion file and a given functional network, computed as a percentage of the total number of voxels implicated in this network. This process was also conducted for patients' functional disconnection maps (Supplementary Figure 1). We did not assess overlap with the structural disconnection maps since these were confined to white matter.

The SCN map (Jackson, 2021) spans five distinct clusters including (1) left frontal regions (left IFG, insula, orbitofrontal cortex, and precentral gyrus), (2) left posterior temporal regions (left pMTG, posterior inferior temporal gyrus, and posterior fusiform gyrus), (3) the bilateral dmPFC, (4) the right IFG (pars orbitalis) and insula, and (5) the right IFG (pars triangularis). The SCN was split into these separate clusters in order to observe spreading disconnection within the SCN beyond lesion site. We extracted the mean percentage of each cluster that overlapped with each patient's lesion map; we then identified whether patients' structural and functional disconnection maps showed any overlap with each SCN cluster that fell outside the patients' lesion.

\subsection{Symptom mapping}

We assessed the patterns of lesion, structural disconnection, and functional disconnection associated with the semantic composite score and executive function performance. Patients' binary lesion segmentations, continuous structural disconnection maps, and continuous functional disconnection maps were separately entered into nonparametric 2-sample t-tests in Randomise (Winkler et al., 2014; https://fsl.fmrib.ox.ac.uk/fsl/fslwiki/Randomise/UserGuide), using 5,000 permutations. Threshold-free cluster enhancement was implemented to identify clusters (Smith \& Nichols, 2009). This analysis was restricted to the 20 patients for whom both the semantic cognition composite and Brixton test scores were available. Each model was set up such that the input was a 4D file containing all patient maps. In each case simultaneous regressors included the size of a given patient's respective input file size (i.e., the overall size of the binary lesion map or unthresholded disconnection map), their semantic composite, and their Brixton performance. Within each model, clusters implicated for a given behavioural measure therefore regressed out the size of the input file as well as performance on the other behavioural measure. A binary mask containing the addition of all patient input files was used. Contrasts were specified such that the resulting output revealed (i) clusters associated with better semantic performance, (ii) clusters associated with poorer semantic performance, 
bioRxiv preprint doi: https://doi.org/10.1101/2021.12.01.470605; this version posted December 2, 2021. The copyright holder for this preprint (which was not certified by peer review) is the author/funder, who has granted bioRxiv a license to display the preprint in perpetuity. It is made available under aCC-BY-NC-ND 4.0 International license.

(iii) clusters associated with better Brixton performance, and (iv) clusters associated with poorer Brixton performance. All resulting t-value maps were thresholded at a value of 2.6 for interpretation. Lesioned/disconnected clusters associated with better behavioural performance reflect better performance relative to the sample mean, rather than absolute improvements in performance as a result of damage. Such clusters were not of explicit interest in the current analysis, so are reported in Supplementary Figure 2. 


\section{Results}

Data for this project are available on the Open Science Framework (https://osf.io/6psqj/). Unthresholded group-level NIFTI files corresponding to the results presented here can be seen on Neurovault (https://neurovault.org/collections/10333/).

\subsection{Lesion profile}

We first characterised the regions most typically lesioned across the sample. The lesion group map reflecting maximum overlap is provided in Figure 1a. An unthresholded view provided in Supplementary Figure 3a. Due to the relative heterogeneity of the lesions (see Figure 1d), this image has a minimum threshold of four cases, while a higher minimum threshold of 19 cases is used for the structural and functional disconnection overlap maps. Lesions encompassed a range of left frontoparietal regions; for each anatomical region extracted from the Harvard-Oxford atlas ${ }^{5}$, we calculated the percentage of the sample $(\mathrm{N}=$ 23 ) that showed some evidence of damage. These regions included the left IFG (pars triangularis, 56.5\%, and pars opercularis, 69.6\%), middle frontal gyrus (MFG; 60.9\%), insular cortex $(60.9 \%)$, precentral gyrus $(82.6 \%)$, postcentral gyrus $(73.9 \%)$, supramarginal gyrus $(65.2 \%)$, and angular gyrus (AG; 65.2\%). In some cases, lesions extended to temporal and occipital regions, including the pMTG (34.8\%), temporo-occipital part of the MTG (39.1\%), superior temporal gyrus (STG; 47.8\%), inferior temporal gyrus (ITG; 34.8\%), planum temporale (52.2\%), temporal pole (43.5\%), lateral occipital cortex (LOC; 69.6\%), and occipital pole (30.4\%). Damage to the temporal pole spared vATL in every case. Some of the damaged described here is not visible in Figure 1a due to the heterogeneity of lesion location. For example, while eight patients show damage to some aspect of the pMTG, this damage does not always fall in the same voxels, meaning this region does not appear to be impacted to this extent in the thresholded overlap.

\subsection{Structural disconnection}

Using patients' lesions in conjunction with the disconnectome function of the BCB Toolkit, we extracted maps of probabilistic spreading white matter structural disconnection for each patient in order to characterise typical patterns of diffuse damage beyond lesion site. The structural disconnection group map reflecting maximum overlap can be seen in Figure 1b. An unthresholded view provided in Supplementary Figure 3b. Extensive structural disconnection was found to be likely throughout the left hemisphere. Twenty-one patients

\footnotetext{
$\overline{5}$ These anatomical regions were thresholded at a value of 30 such that they were mutually exclusive.
} 
showed some evidence of right hemisphere structural disconnection. While disconnection in the left hemisphere was convergent, right hemisphere disconnection was relatively heterogenous, meaning it cannot be observed in Figure $1 \mathrm{~b}$ at the selected threshold of 19 cases (observable at threshold of 17, see Figure S3b). Supplementary Figure 4 shows the mean probability of each tract being disconnected (Figure S4a), as well as estimates of the mean proportion of each tract that was disconnected across the sample (Figure S4b), both estimated using Tractotron (see Section 2.5). This figure also provides visualisations of the structural disconnection overlap map (Figure S4c) and each tract of interest (Figure S4d-k). The mean probability of disconnection was above $60 \%$ for all tracts that were examined. The mean proportion of disconnection was highest for ILF, SLF III and anterior AF. Figure 1d suggests that the patterns of structural disconnection seen in this SA patient sample were relatively homogeneous and highly overlapping, despite their heterogenous lesions. Applying a threshold of ten patients reduces the size (in voxels) of the overall lesion overlap map by $93.5 \%$, while this same threshold reduces the structural disconnection overlap map by only $49.7 \%$.

\subsection{Functional disconnection}

In order to assess the intrinsic functional architecture associated with structural disconnection, we used each participant's lesion as a seed in a resting-state analysis of an independent sample of healthy individuals in CONN to provide maps of functional disconnection. Figure 1c provides the functional disconnection group map reflecting maximum overlap. An unthresholded view provided in Supplementary Figure 3c. The resting-state maps associated with all 23 patients' lesions showed functional disconnection bilaterally of the AG, supramarginal gyrus, superior temporal gyrus, inferior LOC, MFG, precentral gyrus, postcentral gyrus, temporal pole, and temporo-occipital part of the MTG, and of the right insular cortex and superior frontal gyrus. In most cases, patients' functional disconnection maps predicted disconnection of the bilateral IFG (pars orbitalis and pars triangularis; 95.7\%), pMTG (95.7\%), superior LOC (95.7\%), ITG (anterior $=91.3 \%$, posterior $=95.7 \%$, temporo-occipital part $=95.7 \%)$, occipital pole $($ left $=91.3 \%$, right $=$ $87.0 \%)$, aMTG $($ left $=95.7 \%$, right $=82.6 \%)$, and the left insular cortex $(95.7 \%)$ and superior frontal gyrus (95.7\%). These patterns of functional disconnection were relatively homogeneous, with a threshold of ten patients reducing the overall size of the functional disconnection overlap map by only $25.1 \%$ (see Figure $1 \mathrm{~d}$ ). 


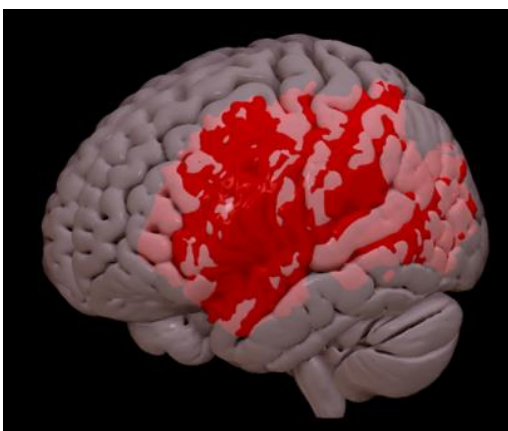

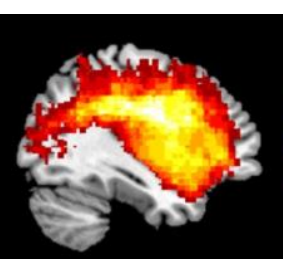

$\mathrm{X}:-38$

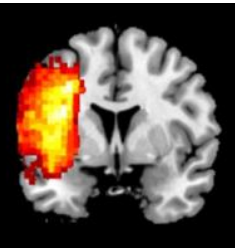

Y: 3

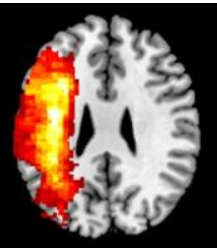

Z: 28

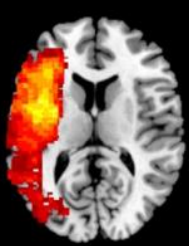

Z: 12

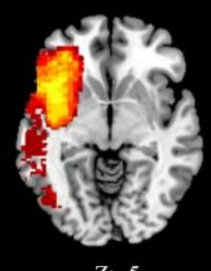

Z: -5

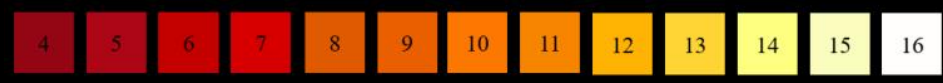

(a) - Lesion Overlap Map

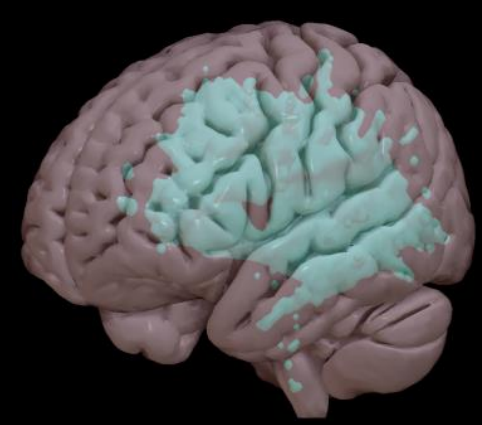

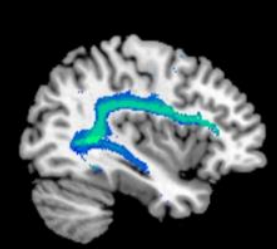

X: -38

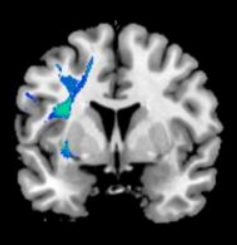

Y: 3

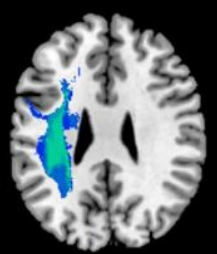

Z: 28

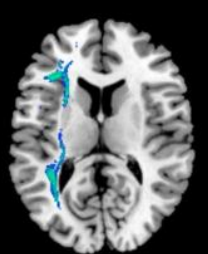

Z: 12

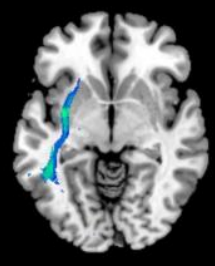

Z: -5

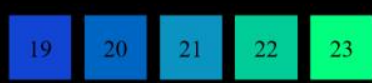

(b) - Strucutral Disconnection Overlap Map

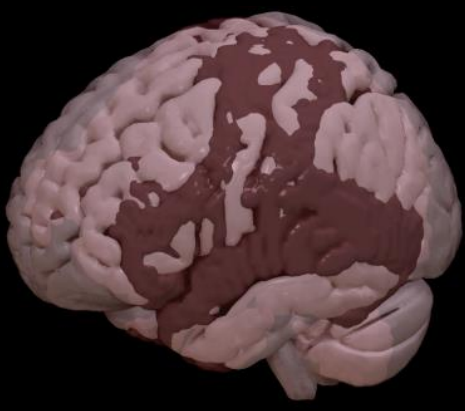

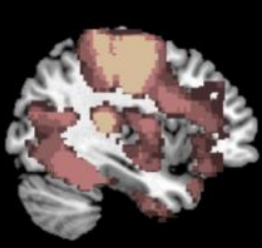

X: -38

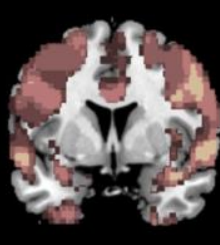

Y: 3

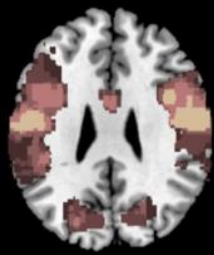

Z: 28

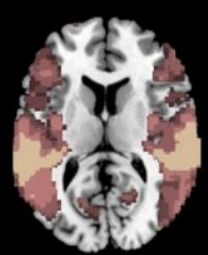

Z: 12

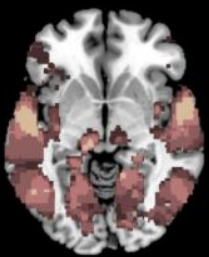

Z: -5

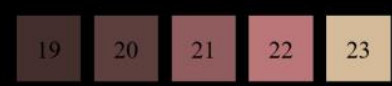

(c) - Functional Disconnection Overlap Map

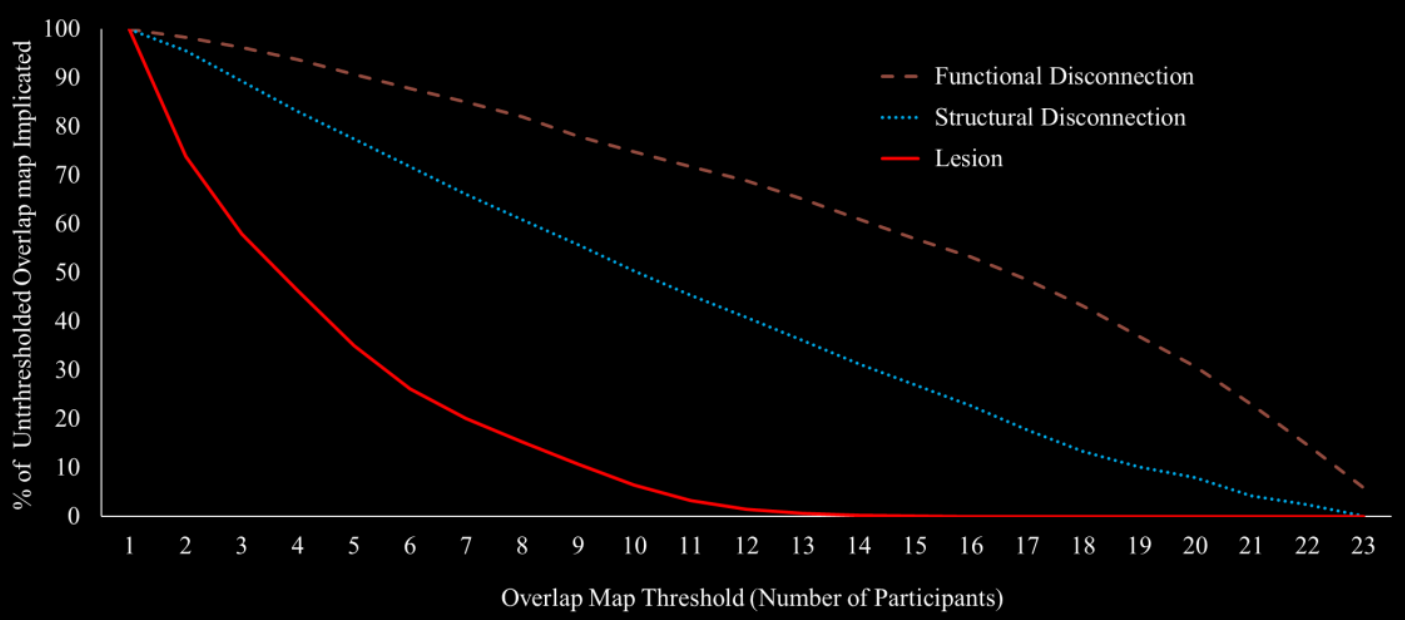

(d) - Overlap Map Thresholding Effects 
bioRxiv preprint doi: https://doi org/10.1101/2021.12.01.470605; this version posted December 2, 2021. The copyright holder for this preprint (which was not certified by peer review) is the author/funder, who has granted bioRxiv a license to display the preprint in perpetuity. It is made available under aCC-BY-NC-ND 4.0 International license.

Figure 1. Maximum overlap for (a) lesion sites thresholded at 4 cases, (b) structural disconnection maps, generated using the BCB Toolkit, thresholded at 19 cases, and (c) functional disconnection maps, generated using CONN, thresholded at 19 cases. 3D rendering generated in SurfIce. (d) Visualisation of the numbers of cases showing overlapping lesions, structural disconnection (confined to white matter) and functional disconnection (confined to grey matter), expressed as a percentage of the total number of voxels damaged or disconnected for at least one participant. This figure demonstrates the homogeneity of patterns of anticipated structural and functional disconnection, relative to the lesion overlap map. $N=23$.

DESCRIPTIVE CAPTION FOR TEXT-TO-SPEECH: Figure 1 presents overlap maps for the measures of lesion, structural disconnection, and functional disconnection. Figure 1a presents lesion overlap between 4 and 16 cases. Lesions are confined to the left hemisphere and are frontoparietal, peaking in the precentral and middle frontal gyri. Figure 1b presents structural disconnection overlap between 19 and 23 cases. Structural disconnection is left lateralised at this threshold and shows maximal overlap with the superior longitudinal fasciculus and inferior fronto-occipital fasciculus. Figure $1 c$ presents functional disconnection overlap between 19 and 23 cases. Functional disconnection is bilateral and extensive, subsuming many regions throughout the cortex and peaking in the precentral and postcentral gyri. A line graph in Figure 1d reflects the homogeneity of structural and functional disconnection relative to lesion location, with increasing thresholds reducing the overall size of the lesion overlap map at a much higher rate than for either disconnection measure.

\subsection{Damage and disconnection within functional networks}

\subsubsection{Mean percent lesioned}

We observed the extent of lesion to each functional network of interest. The mean percentage of voxels lesioned in left hemisphere aspects of DMN, semantic non-control, $\mathrm{SCN}, \mathrm{SCN}+\mathrm{MDN}$ and MDN networks is shown in Figure 2a. The greatest damage was seen in SCN regions (Figure 2d), followed by SCN+MDN (Figure 2e). The MDN (Figure 2f) and non-control semantic regions (Figure 2c) showed more modest damage, and damage to the DMN was minimal (Figure 2b). An equivalent analysis of functional disconnection is provided in Supplementary Figure 1. Most ( $\geq 74.8 \%)$ of the SCN, MDN, SCN+MDN and core semantic regions were functionally disconnected across the sample. The DMN was also affected but across less than half of the network (44.1\%). As seen in Supplementary Table 3, a significantly smaller percentage of the DMN was lesioned than other functional networks, excluding core semantic regions. A significantly smaller percentage of the DMN was also functionally disconnected when compared to all other networks. The extent of lesion and functional disconnection did not differ significantly between other networks of interest (see Supplementary Table 3). 
bioRxiv preprint doi: https://doi org/10.1101/2021.12 01.470605. this version posted December 2 2021. The copyright holder for this preprint (which was not certified by peer review) is the author/funder, who has granted bioRxiv a license to display the preprint in perpetuity. It is made available under aCC-BY-NC-ND 4.0 International license.

\subsubsection{Spreading SCN disconnection}

In order to understand typical damage to key semantic control regions in SA, we next identified SCN components most likely to be lesioned across the sample and looked for evidence of spreading structural and functional disconnection to SCN regions beyond the lesion site. The SCN map was split into its distinct clusters (see Section 2.5). Table 1 presents the percentage of each cluster lesioned for each patient, as well as a binary measure of whether this cluster showed evidence of structural or functional disconnection. Most cases had lesions in the left frontal cluster (16/23). All patients had structural and functional disconnection to this cluster, including when this cluster was not itself lesioned. A smaller number of cases had a lesion encompassing a left posterior temporal cluster (10/23) but again, all patients showed evidence of its structural and functional disconnection. A majority of cases (21/23) showed evidence of structural and functional disconnection to the bilateral dmPFC cluster, despite only two cases showing direct lesion to this site. Three patients did not show direct lesion to any of the three left hemisphere SCN nodes. Even in these cases, diffuse connection was still frequently observed across the network. The two right hemisphere frontal clusters were spared in terms of lesion and structural disconnection but were both functionally disconnected in all but one patient.

Overall, these results suggest maximum impact to areas implicated in semantic control in SA patients, with some damage to core semantic and domain-general control and relative sparing of the DMN. Patients reliably show evidence of spreading structural and functional disconnection to left hemisphere sites in the SCN that are not directly lesioned. 
bioRxiv preprint doi: https://doi.org/10.1101/2021.12.01.470605; this version posted December 2, 2021. The copyright holder for this preprint (which was not certified by peer review) is the author/funder, who has granted bioRxiv a license to display the preprint in perpetuity. It is made available under aCC-BY-NC-ND 4.0 International license.

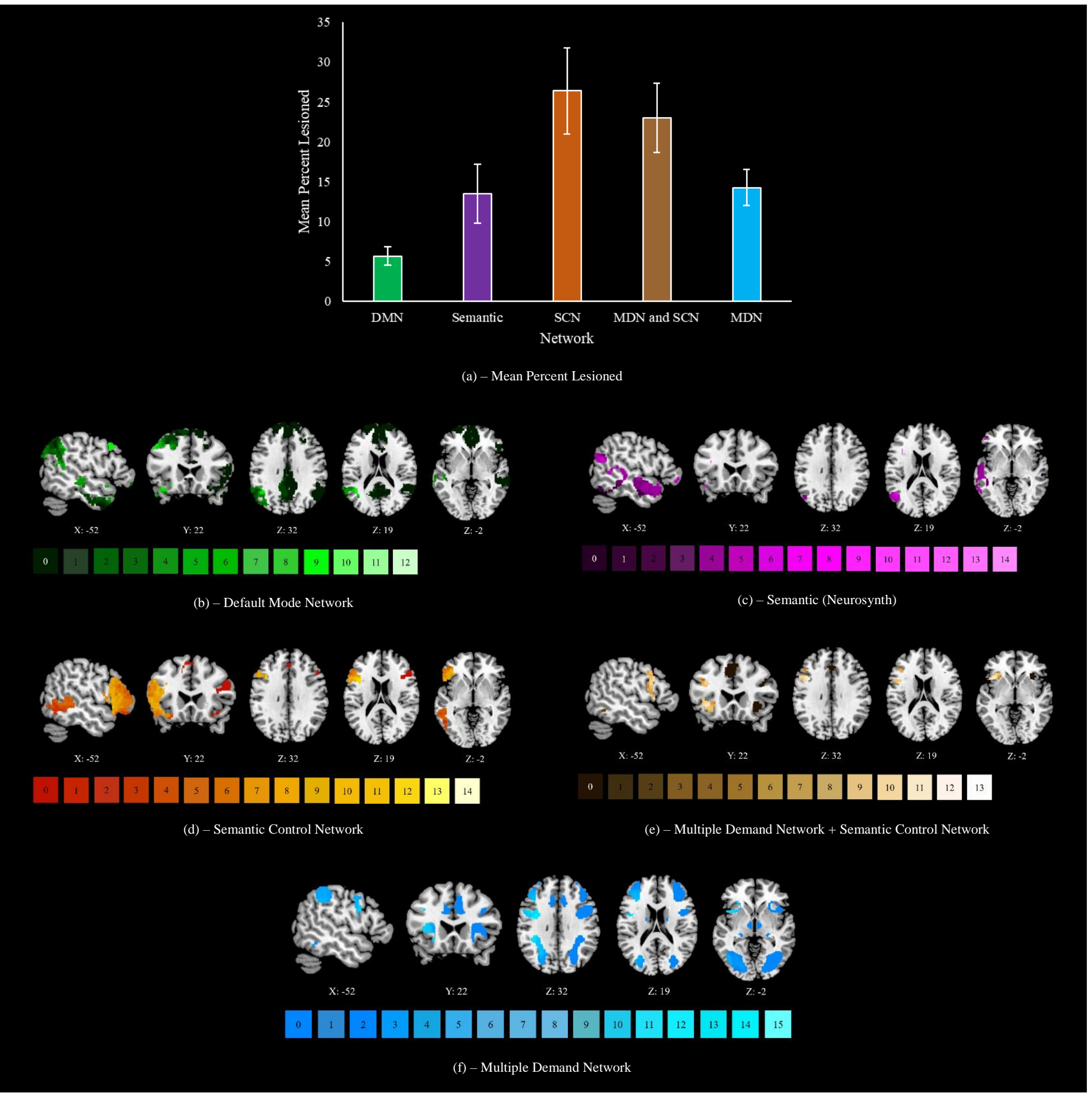

Figure 2. (a) The mean percentage of each network of interest (confined to the left hemisphere) overlapping with patient lesion files. DMN = default mode network, $S C N=$ semantic control network, $M D N=$ multiple demand network. Networks are visualised for $(b)$ the DMN, (c) core semantic regions, (d) the $S C N$, (e) areas common to the MDN and $S C N$, and (f) the MDN. Any right hemisphere aspects of each network are visualised, but were never impacted by lesion. Keys under each map reflect the number of patients with lesion to a given voxel. $N=23$.

DESCRIPTIVE CAPTION FOR TEXT-TO-SPEECH: Figure 2a reflects the mean percentage lesioned for each network of interest. This peaks in the semantic control network at $26 \%$, followed by areas shared between the multiple demand and semantic 
control networks at $23 \%$, core semantic regions and regions exclusive to the multiple demand network both at $14 \%$, and the default mode network at $6 \%$. Locations of most frequent damage are displayed for each network in following sections. Figure $\mathbf{2 b}$ presents the default mode network, lesion peaks in the angular gyrus and insular cortex at a threshold of 12 cases. Figure $2 \mathrm{c}$ presents core semantic regions, lesion peaks in the inferior frontal gyrus pars opercularis at a threshold of $\mathbf{1 4}$ cases. Figure $\mathbf{2 d}$ presents the semantic control network, lesion peaks in the inferior frontal gyrus pars opercularis at a threshold of 14 cases. Figure $2 \mathrm{e}$ presents regions shared by the semantic control and multiple demand networks, lesion peaks in the middle frontal and precentral gyri at 13 cases. Figure $2 \mathrm{f}$ presents the multiple demand network, lesion peaks in the precentral gyrus at a threshold of 15 cases. 
Table 1

Lesion, structural disconnection (SDC), and functional disconnection (FDC) to semantic control network clusters.

\begin{tabular}{|c|c|c|c|c|c|c|c|c|c|c|c|c|c|c|c|}
\hline \multirow[b]{2}{*}{ Patient } & \multicolumn{3}{|c|}{$\begin{array}{l}\text { Left IFG, insula, OFC, \& } \\
\text { precentral gyrus }\end{array}$} & \multicolumn{3}{|c|}{ Left pMTG, pITG, \& pFG } & \multicolumn{3}{|c|}{ Bilateral dmPFC } & \multicolumn{3}{|c|}{ Right IFG (pars orbitalis) } & \multicolumn{3}{|c|}{ Right IFG (pars triangularis) } \\
\hline & Lesion & SDC & FDC & Lesion & SDC & FDC & Lesion & SDC & FDC & Lesion & SDC & FDC & Lesion & SDC & FDC \\
\hline P01 & $x$ & $\checkmark$ & $\checkmark$ & $46 \%$ & $\checkmark$ & $\checkmark$ & $x$ & $x$ & $x$ & $x$ & $x$ & $\checkmark$ & $x$ & $x$ & $\checkmark$ \\
\hline $\mathrm{P} 02$ & $29 \%$ & $\checkmark$ & $\checkmark$ & $39 \%$ & $\checkmark$ & $\checkmark$ & $x$ & $\checkmark$ & $\checkmark$ & $x$ & $x$ & $\checkmark$ & $x$ & $x$ & $\checkmark$ \\
\hline $\mathrm{P} 03$ & $x$ & $\checkmark$ & $\checkmark$ & $x$ & $\checkmark$ & $\checkmark$ & $x$ & $x$ & $x$ & $x$ & $x$ & $x$ & $x$ & $x$ & $x$ \\
\hline P04 & $45 \%$ & $\checkmark$ & $\checkmark$ & $20 \%$ & $\checkmark$ & $\checkmark$ & $x$ & $\checkmark$ & $\checkmark$ & $x$ & $x$ & $\checkmark$ & $x$ & $x$ & $\checkmark$ \\
\hline P05 & $x$ & $\checkmark$ & $\checkmark$ & $9 \%$ & $\checkmark$ & $\checkmark$ & $x$ & $\checkmark$ & $\checkmark$ & $x$ & $x$ & $\checkmark$ & $x$ & $x$ & $\checkmark$ \\
\hline P06 & $48 \%$ & $\checkmark$ & $\checkmark$ & $x$ & $\checkmark$ & $\checkmark$ & $x$ & $\checkmark$ & $\checkmark$ & $x$ & $x$ & $\checkmark$ & $x$ & $x$ & $\checkmark$ \\
\hline P07 & $x$ & $\checkmark$ & $\checkmark$ & $3 \%$ & $\checkmark$ & $\checkmark$ & $x$ & $x$ & $\checkmark$ & $x$ & $x$ & $\checkmark$ & $x$ & $x$ & $\checkmark$ \\
\hline P08 & $80 \%$ & $\checkmark$ & $\checkmark$ & $25 \%$ & $\checkmark$ & $\checkmark$ & $x$ & $\checkmark$ & $\checkmark$ & $x$ & $x$ & $\checkmark$ & $x$ & $x$ & $\checkmark$ \\
\hline P09 & $8 \%$ & $\checkmark$ & $\checkmark$ & $x$ & $\checkmark$ & $\checkmark$ & $x$ & $\checkmark$ & $\checkmark$ & $x$ & $x$ & $\checkmark$ & $x$ & $x$ & $\checkmark$ \\
\hline P10 & $72 \%$ & $\checkmark$ & $\checkmark$ & $38 \%$ & $\checkmark$ & $\checkmark$ & $x$ & $\checkmark$ & $\checkmark$ & $x$ & $x$ & $\checkmark$ & $x$ & $x$ & $\checkmark$ \\
\hline P11 & $48 \%$ & $\checkmark$ & $\checkmark$ & $1 \%$ & $\checkmark$ & $\checkmark$ & $x$ & $\checkmark$ & $\checkmark$ & $x$ & $x$ & $\checkmark$ & $x$ & $x$ & $\checkmark$ \\
\hline P12 & $63 \%$ & $\checkmark$ & $\checkmark$ & $x$ & $\checkmark$ & $\checkmark$ & $3 \%$ & $\checkmark$ & $\checkmark$ & $x$ & $x$ & $\checkmark$ & $x$ & $x$ & $\checkmark$ \\
\hline $\mathrm{P} 13$ & $19 \%$ & $\checkmark$ & $\checkmark$ & $x$ & $\checkmark$ & $\checkmark$ & $x$ & $\checkmark$ & $\checkmark$ & $x$ & $x$ & $\checkmark$ & $x$ & $x$ & $\checkmark$ \\
\hline P14 & $x$ & $\checkmark$ & $\checkmark$ & $x$ & $\checkmark$ & $\checkmark$ & $x$ & $\checkmark$ & $\checkmark$ & $x$ & $x$ & $\checkmark$ & $x$ & $x$ & $\checkmark$ \\
\hline P15 & $5 \%$ & $\checkmark$ & $\checkmark$ & $x$ & $\checkmark$ & $\checkmark$ & $x$ & $\checkmark$ & $\checkmark$ & $x$ & $x$ & $\checkmark$ & $x$ & $x$ & $\checkmark$ \\
\hline P16 & $24 \%$ & $\checkmark$ & $\checkmark$ & $54 \%$ & $\checkmark$ & $\checkmark$ & $x$ & $\checkmark$ & $\checkmark$ & $x$ & $x$ & $\checkmark$ & $x$ & $x$ & $\checkmark$ \\
\hline P17 & $x$ & $\checkmark$ & $\checkmark$ & $x$ & $\checkmark$ & $\checkmark$ & $x$ & $\checkmark$ & $\checkmark$ & $x$ & $x$ & $\checkmark$ & $x$ & $x$ & $\checkmark$ \\
\hline P18 & $35 \%$ & $\checkmark$ & $\checkmark$ & $x$ & $\checkmark$ & $\checkmark$ & $x$ & $\checkmark$ & $\checkmark$ & $x$ & $x$ & $\checkmark$ & $x$ & $x$ & $\checkmark$ \\
\hline P19 & $64 \%$ & $\checkmark$ & $\checkmark$ & $x$ & $\checkmark$ & $\checkmark$ & $4 \%$ & $\checkmark$ & $\checkmark$ & $x$ & $x$ & $\checkmark$ & $x$ & $x$ & $\checkmark$ \\
\hline P20 & $20 \%$ & $\checkmark$ & $\checkmark$ & $x$ & $\checkmark$ & $\checkmark$ & $x$ & $\checkmark$ & $\checkmark$ & $x$ & $x$ & $\checkmark$ & $x$ & $x$ & $\checkmark$ \\
\hline $\mathrm{P} 21$ & $x$ & $\checkmark$ & $\checkmark$ & $x$ & $\checkmark$ & $\checkmark$ & $x$ & $x$ & $\checkmark$ & $x$ & $x$ & $\checkmark$ & $x$ & $x$ & $\checkmark$ \\
\hline P22 & $82 \%$ & $\checkmark$ & $\checkmark$ & $46 \%$ & $\checkmark$ & $\checkmark$ & $x$ & $\checkmark$ & $\checkmark$ & $x$ & $x$ & $\checkmark$ & $x$ & $x$ & $\checkmark$ \\
\hline $\mathrm{P} 23$ & $93 \%$ & $\checkmark$ & $\checkmark$ & $x$ & $\checkmark$ & $\checkmark$ & $x$ & $\checkmark$ & $\checkmark$ & $x$ & $x$ & $\checkmark$ & $x$ & $x$ & $\checkmark$ \\
\hline Group Mean & $46 \%$ & N/A & N/A & $28.1 \%$ & N/A & N/A & $3.3 \%$ & N/A & N/A & $0 \%$ & N/A & N/A & $0 \%$ & N/A & N/A \\
\hline Patients Impacted & 16 & 23 & 23 & 10 & 23 & 23 & 2 & 19 & 21 & 0 & 0 & 22 & 0 & 0 & 22 \\
\hline
\end{tabular}

Note: Semantic control network clusters taken from Jackson (2021). Lesion columns reflect the percentage of each cluster impacted by a given patient's lesion. In SDC and FDC columns, ticks reflect cases where these was any overlap with a cluster and patients' structural disconnection and functional disconnection maps, respectively. Crosses occur when a given cluster was not lesioned/disconnected. Patients Impacted reflects the number of patients for whom the given cluster was lesioned/disconnected. IFG $=$ inferior frontal gyrus, OFC $=$ orbitofrontal cortex, $\mathrm{pMTG}=$ posterior middle temporal gyrus, $\mathrm{pITG}=$ posterior inferior temporal gyrus, $\mathrm{pFG}=$ posterior fusiform gyrus, $\mathrm{dmPFC}=$ dorsomedial prefrontal cortex, $\mathrm{SDC}=$ structural disconnection, $\mathrm{FDC}=$ functional disconnection. 


\subsection{Symptom mapping}

Next, we identified lesioned and disconnected voxels associated with poorer behavioural performance. Damage or disconnection was used to predict lower scores on the semantic cognition composite (comprising word and picture semantic associations and comprehension of ambiguous words) and the Brixton Spatial Anticipation Test, which probes non-verbal cognitive control, with results thresholded at $\mathrm{t}>2.6$. At this threshold, clusters associated with semantic and executive performance were mutually exclusive with no overlapping voxels within each analysis. Visual representations of the functional networks referred to here can be seen in Figure 2.

\subsubsection{Lesion-symptom mapping}

Lesioned clusters associated with lower semantic cognition composite and Brixton scores can be seen in Figure 3a. Clusters implicated in semantic cognition showed overlap with the SCN, particularly in the anterior IFG, MFG, frontal pole, pMTG, and temporooccipital part of the MTG. Overlap with the MDN was observed in the posterior IFG/inferior frontal sulcus, MFG, frontal pole, inferior LOC, intraparietal sulcus, and superior parietal lobule. Overlap with both the DMN and core semantic regions was observed in the frontal pole, pMTG, temporo-occipital part of the MTG, and temporo-occipital part of the ITG. Outside of these networks, clusters were observed in the precentral gyrus, postcentral gyrus, and occipital pole. Clusters associated with poorer performance on the Brixton test showed overlap with the SCN in the posterior IFG, MFG, SFG, and precentral gyrus. Overlap with the MDN was observed in intraparietal sulcus, supramarginal gyrus and postcentral gyrus. Overlap with the DMN occurred in the SFG, while core semantic regions were not implicated.

\subsubsection{Structural disconnection-symptom mapping}

The results of the structural disconnection analysis can be seen in Figure $3 b$.

Structurally disconnected clusters associated with lower semantic cognition composite scores were minimal, but were confined to the left hemisphere in regions including the frontal pole, precentral and postcentral gyri, pMTG, and occipital pole. These very small clusters were proximal to the regions identified in the lesion analysis, and were not large enough to implicate specific white matter tracts. There were no structurally disconnected clusters associated with poor semantic cognition in the right hemisphere. In contrast, poorer Brixton performance was associated with a pattern of interhemispheric structural disconnection across 
bioRxiv preprint doi: https://doi org/10.1101/2021.12.01.470605; this version posted December 2,2021 . The copyright holder for this preprint (which was not certified by peer review) is the author/funder, who has granted bioRxiv a license to display the preprint in perpetuity. It is made available under aCC-BY-NC-ND 4.0 International license.

the corpus callosum, consistent with a role of interhemispheric connectivity in executive control in this visuo-spatial task.

\subsubsection{Functional disconnection-symptom mapping}

The results of the functional disconnection analysis are shown in Figure 3c. Lower semantic cognition composite scores were associated with functional disconnection in left frontal orbital cortex, left temporal pole, right frontal pole, and bilateral cerebellum. Poorer Brixton performance was associated with functional disconnection in bilateral SFG, bilateral cerebellum, and the right superior parietal lobule. In both cases, these clusters were sparse, and too small to implicate functional networks.

In summary, left hemisphere lesion sites associated with poorer semantic cognition are mutually exclusive from but adjacent to those implicated in executive function (in line with previous studies showing that the semantic control network lies between DMN and MDN regions on the cortical surface; Davey et al., 2016; Wang et al., 2020). In contrast, the substrates for structural and functional disconnection are more divergent across semantic and executive tasks. This is particularly the case for structural disconnection, since patterns associated with poor semantic cognition are left-lateralised, while executive dysfunction is associated with cross-hemispheric disconnection. 
bioRxiv preprint doi: https://doi.org/10.1101/2021.12.01.470605; this version posted December 2, 2021. The copyright holder for this preprint (which was not certified by peer review) is the author/funder, who has granted bioRxiv a license to display the preprint in perpetuity. It is made available under aCC-BY-NC-ND 4.0 International license.

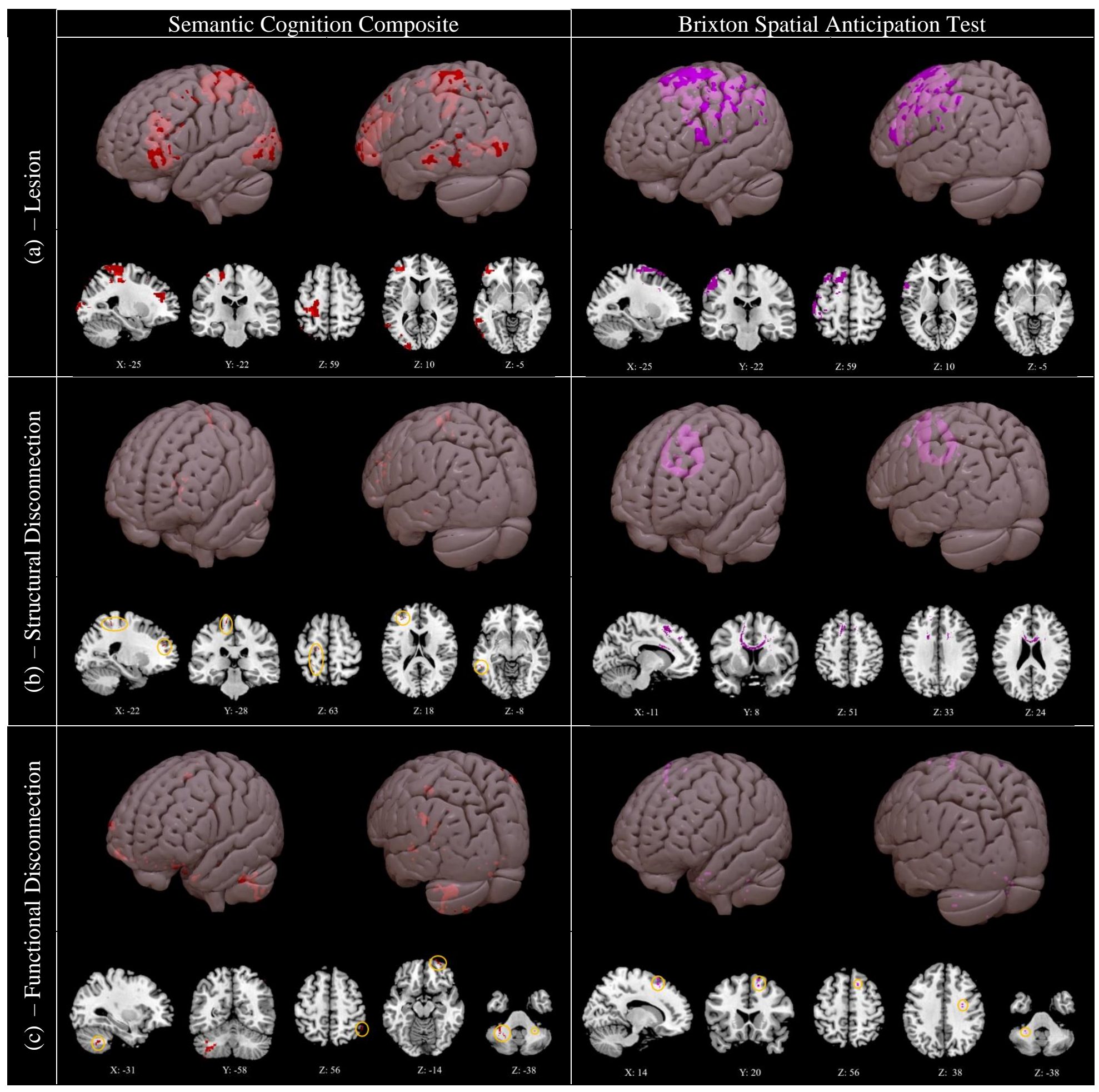

Figure 3. Clusters associated with lower semantic cognition composite scores (left) and lower scores on the Brixton Spatial Anticipation Test (right), for (a) lesion, (b) structural disconnection, and (c) functional disconnection data. Generated using non-parametric permutation tests in Randomise with threshold-free cluster enhancement. Highlighted voxels have a $t$-value of 2.6 or higher. Small clusters are highlighted in orange circles. $3 D$ rendering generated in SurfIce. $N=20$.

DESCRIPTIVE CAPTION FOR TEXT-TO-SPEECH: Figure 3 presents clusters identified in symptom mapping as associated with poorer performance. This is done for both the semantic composite score and Brixton Spatial Anticipation Test, for the measures of lesion, structural 
bioRxiv preprint doi: https://doi.org/10.1101/2021.12.01.470605; this version posted December 2, 2021. The copyright holder for this preprint (which was not certified by peer review) is the author/funder, who has granted bioRxiv a license to display the preprint in perpetuity. It is made available under aCC-BY-NC-ND 4.0 International license.

disconnection, and functional disconnection. Lesioned clusters associated with poorer semantic and Brixton performance are large and left lateralised, and reflect the regions listed in section 3.5.1. Structurally disconnected clusters are small and left lateralised for semantic cognition, reflecting regions listed in section 3.5.2., while for poorer Brixton performance one large cluster is observed across the corpus callosum. Functionally disconnected clusters are small and sparse for both measures, and reflect the regions listed in section 3.5.3.

\section{Discussion}

This study characterised lesion location, structural disconnection, and functional disconnection in semantic aphasia (SA) patients who have impaired semantic control following left hemisphere stroke. Lesions were most common within the semantic control network ( $\mathrm{SCN}$ ), and areas commonly responsive to semantic control and executive function (the multiple demand network (MDN); Duncan, 2010). Lesions were heterogenous as is typical of this population (e.g., Chapman et al., 2020; Hallam et al., 2018), with many but not all cases having frontal damage. When mapping behavioural performance to lesion site, more severe deficits of semantic cognition and non-semantic cognitive control were associated with lesions in proximal areas of the left frontoparietal cortex. This result is consistent with studies from healthy participants suggesting that semantic and domain-general executive regions are supported by adjacent left hemisphere regions (Davey et al., 2016; Gao et al., 2021). Measures of structural and functional disconnection, anticipated from lesion location, showed extensive effects spreading beyond the local lesion site, frequently affecting structurally intact semantic control regions. This result may account for the similarity of control deficits seen in SA patients despite divergent lesion profiles. Associations between functional disconnection and cognitive performance were limited. Insight into semantic performance from structural disconnection was similarly limited, but small frontal, parietal and posterior temporal clusters in the left hemisphere, proximal to lesioned substrates, were highlighted. Poorer executive function was predicted by interhemispheric structural disconnection across the corpus callosum. These different patterns of structural disconnection associated with semantic cognition and cognitive control are consistent with previous studies showing that the $\mathrm{SCN}$ is largely left-lateralised, while domain-general executive function is supported by the bilateral MDN (Fedorenko et al., 2013; Gonzalez Alam et al., 2019). In this way, we can explain why similar left hemisphere clusters are associated with poor semantic cognition and cognitive control and provide an account of the hemispheric differences in structural disconnection associated with these deficits. 
bioRxiv preprint doi: https://doi.org/10.1101/2021.12.01.470605; this version posted December 2, 2021. The copyright holder for this preprint (which was not certified by peer review) is the author/funder, who has granted bioRxiv a license to display the preprint in perpetuity. It is made available under aCC-BY-NC-ND 4.0 International license.

Previous descriptions of the SCN have highlighted left IFG and pMTG as key structures within this functional network (Jackson, 2021; Jefferies, 2013; Jefferies et al., 2019; Lambon Ralph et al., 2017; Noonan et al., 2013), explaining why semantic impairment was predicted by both lesions and structural disconnection of these regions. Topographically, the SCN lies between the DMN and MDN (Davey et al., 2016; Wang et al., 2020), and this network has been proposed as a functional nexus between core semantic regions and domaingeneral control regions, facilitating the integration of these processes (Davey et al., 2016). Accordingly, the current results revealed adjacent but mutually exclusive frontoparietal lesions resulting in poorer semantic cognition and executive function, consistent with prior evidence of adjacent substrates for these functions (Wang et al., 2018). This may account for the finding that some SA patients present with executive dysfunction while others do not (Thompson et al., 2018). Indeed, 14 of the current 23 patients presented with some degree of executive dysfunction, with performance on the Brixton Spatial Anticipation Test (Burgess \& Shallice, 1997) positively correlating with semantic performance. It may be that impaired semantic control does not necessitate executive impairment (Chapman et al., 2020), but that the proximity of these substrates means that these functions are frequently impaired together. Frequent damage to substrates underlying semantic or domain-general control or both in SA may give rise to broad deficits in constraining internal aspects of cognition (Souter et al., 2021; Stampacchia et al., 2018), reflected in heightened susceptibility to external cues and miscues in semantic retrieval (Jefferies et al., 2008; Noonan et al., 2010), along with strong effects of distractors in semantic decision-making (Corbett et al., 2011; Noonan et al., 2010).

While the lesioned substrates associated with semantic cognition included SCN regions as expected, areas outside this network were also implicated, including the LOC and postcentral gyrus. It is worth noting that the semantic composite score derived here reflects general semantic cognition (albeit performance on highly demanding heteromodal tasks) rather than semantic control specifically, and this may account for the inclusion of regions not typically associated with controlled processing. Evidence has suggested the involvement of the LOC in the visual features of concepts (Coutanche \& Thompson-Schill, 2015), while the postcentral gyrus has been implicated in sensorimotor representation (Kropf et al., 2019). Furthermore, the LOC has been shown to decode category- and task-related semantic information (Wang et al., 2021), which may benefit semantic retrieval. Similarly, the postcentral gyrus has been implicated in the performance of divergent thinking tasks, which require the generation of alternative uses of objects (Cogdell-Brooke et al., 2020). Such a 
bioRxiv preprint doi: https://doi.org/10.1101/2021.12.01.470605; this version posted December 2, 2021. The copyright holder for this preprint (which was not certified by peer review) is the author/funder, who has granted bioRxiv a license to display the preprint in perpetuity. It is made available under aCC-BY-NC-ND 4.0 International license.

process is comparable to semantic control in requiring focus on subordinate conceptual information, as well as mental manipulation of objects. Finally, the LOC and postcentral gyrus are adjacent to the pMTG and dorsal AG, respectively, two nodes that have been implicated in semantic control (Hodgson et al., 2021; Noonan et al., 2013). Ultimately, while the functional contribution of the LOC and postcentral gyrus are not fully understood, these regions may support conceptual retrieval by either representing the features of concepts or by supporting semantic decision-making.

Prior studies investigating the predictive value of indirect measures of structural and functional disconnection (inferred from lesion location, as in the current study) have yielded inconsistent results. Salvalaggio et al. (2020) provided evidence that structural disconnection is comparable to lesion location in its ability to predict post-stroke deficits in several domains, while the utility of indirect measures of functional disconnection appeared negligible. In a re-analysis of data from Salvalaggio et al. (2020), Cohen et al. (2021) conversely demonstrated that lesion network maps (analogous to indirect functional disconnection) explained comparable variance to lesion location and structural disconnection in predicting post-stroke impairment. Prior research has similarly demonstrated the utility of indirectly measured lesion network mapping in predicting post-stroke symptoms including amnesia (Ferguson et al., 2019) and depression (Padmanabhan et al., 2019). Halai et al. (2020) directly measured structural disconnection using diffusion weighted imaging data, and found no added benefit relative to direct observations of abnormal tissue when predicting post-stroke aphasia, citing tight coupling between lesion and disconnection as a possible cause. This is consistent with our observation that the small clusters of structural disconnection associated with deficits in semantic cognition largely followed the lesioned areas, although a different pattern was found for executive dysfunction. Hope et al. (2018) similarly found limited predictive value of indirectly measured structural disconnection beyond lesion location for predicting aphasia severity, while other studies have suggested unique contributions from such measures (Del Gaizo et al., 2017; Kristinsson et al., 2021). It may be that structural disconnection is unlikely to explain unique variation in behavioural performance beyond lesion location when patients have been selected to show particular deficits associated with areas of cortex that are lesioned, as was the case for semantic deficits in our sample. However, since stroke lesions are typically unilateral, structural disconnection may be more likely to explain unique variance in other domains associated with bilateral networks, including executive dysfunction. This is consistent with prior evidence 
bioRxiv preprint doi: https://doi.org/10.1101/2021.12.01.470605; this version posted December 2, 2021. The copyright holder for this preprint (which was not certified by peer review) is the author/funder, who has granted bioRxiv a license to display the preprint in perpetuity. It is made available under aCC-BY-NC-ND 4.0 International license.

demonstrating the utility of structural disconnection in reflecting inter-hemispheric networks (Thiebaut de Schotten et al., 2020). Clusters highlighted by functional disconnection in the current study were limited but did implicate the left cerebellum in semantic cognition, a finding not seen in lesion-symptom mapping. The functional significance of the cerebellum for semantic cognition is unclear, although it is reliably activated in neuroimaging studies (Buckner, 2013; Stoodley \& Schmahmann, 2009).

Our findings are consistent with emerging accounts of the lateralisation of semantic control functions. Clusters associated with demanding semantic cognition were small but leftlateralised and highlighted the SCN; contrasts of hard over easy semantic judgements in neuroimaging studies of healthy participants also reveal a highly left-lateralised network (Jackson, 2021; Noonan et al., 2013; although this may be partially attributable to the predominant use of verbal stimuli in semantic tasks, see Rice et al., 2015), while the ventral ATL's role in long-term semantic representation is highly bilateral (Gonzalez Alam et al., 2019; Rice et al., 2015). Conversely, executive performance on a demanding visual-spatial task was predicted by interhemispheric structural disconnection across the corpus callosum, indicating that this task may be supported by a more bilateral network, in line with prior work (e.g., Bodini et al., 2013; Johnson et al., 2017; Schulte \& Müller-Oehring, 2010).

Neuroimaging studies show that bilateral activation underlies executive function (Camilleri et al., 2018; Fedorenko et al., 2013) and (especially in visual-spatial tasks), the most robust responses are often right-lateralised (Dick et al., 2019; Gonzalez Alam et al., 2018). A recent study found that control networks show different patterns of connectivity across the hemispheres, with left-lateralised control regions showing stronger connectivity with heteromodal regions of the default mode network (Gonzalez Alam et al., 2021). In this way, the left lateralised nature of the semantic control network revealed by our analysis may be adaptive, allowing control regions to separate from visual-spatial responses when internal aspects of cognition are constrained.

There are some important limitations of this study. First, as data were collated across three separate samples of SA patients, there were a limited number of tests on which all patients had been assessed. Our analysis of executive function was confined to the Brixton Spatial Anticipation Test. While performance on Raven's Coloured Progressive Matrices (Raven, 1962) was also available for each patient, scores across these two tests did not meet the necessary assumptions of principal components analysis, and so a composite score was not derived. While the Brixton test is a sensitive measure of executive impairment (van den 
Berg et al., 2009), the use of a broader set of tests would be helpful in establishing the relationships between lesion and disconnection to more general deficits of cognitive control. Secondly, our approach examined impaired semantic cognition across tasks but not behavioural measures specific to semantic control. Prior investigations have consistently concluded that SA patients present with preserved semantic storage and impaired controlled retrieval (e.g., Jefferies \& Lambon Ralph, 2006; but see Chapman et al., 2020 for an alternative view). However, in the absence of a comparison group, such as patients with SD, we cannot rule out the possibility that aspects of our results reflect impaired semantic processing more generally. A comparison of disconnection in SA and SD patients would provide additional insights into how these conditions differentially impact networks associated with controlled retrieval and core semantic representation. A sample of patients who had all completed a larger range of tests with high semantic control demands may allow for the extraction of separate semantic control and core semantic cognition composite scores. Third, our measures of functional and structural disconnection were indirect. Direct measures of resting state functional connectivity have been previously shown to predict post-stroke symptoms to a greater extent than indirectly measured functional disconnection (Salvalaggio et al., 2020). Furthermore, Cohen et al. (2021) recently argued that methodological factors such as the sample size and the MRI field strength for the normative sample might influence the efficacy of indirect measures of functional disconnection. They suggest a normative sample size of at least 150-200 before estimates of connectivity stabilise within cohorts, while our sample consisted of 141 participants; this may contribute to the low predictive utility of functional disconnection in the current analysis.

\subsection{Conclusion}

We assessed patterns of spreading structural and functional disconnection in lefthemisphere stroke patients with semantic aphasia. These results highlight damage to the SCN in this group, both as a direct result of lesions and following spreading disconnection. We show that semantic and domain-general executive control are supported by adjacent substrates in the left hemisphere and yet associated with distinct patterns of structural disconnection that are left-lateralised and bilateral, respectively. 


\section{References}

Agosta, F., Henry, R. G., Migliaccio, R., Neuhaus, J., Miller, B. L., Dronkers, N. F., Brambati, S. M., Filippi, M., Ogar, J. M., Wilson, S. M., \& Gorno-Tempini, M. L. (2010). Language networks in semantic dementia. Brain, 133(1), 286-299. https://doi.org/10.1093/brain/awp233.

Almairac, F., Herbert, G., Moritz-Gasser, S., Menjot de Champfleur, N., \& Duffau, H. (2015). The left inferior fronto-occipital fasciculus subserves language semantics: A multilevel lesion study. Brain Structure and Function, 220, 1983-1995. https://doi.org/10.1007/s00429-014-0773-1.

Avants, B. B., Tustison, N. J., Song, G., Cook, P. A., Klein, A., \& Gee, J. C. (2011). A reproducible evaluation of ANTs similarity metric performance in brain image registration. NeuroImage, 54(3), 2033-2044. https://doi.org/10.1016/j.neuroimage.2010.09.025.

Avants, B. B., Tustison, N. J., Stauffer, M., Song, G., Wu, B., \& Gee, J. C. (2014). The Insight ToolKit image registration framework. Frontiers in Neuroscience, 8, 44. https://doi.org/10.3389/fninf.2014.00044.

Badre, D., \& Wagner, A. D. (2007). Left ventrolateral prefrontal cortex and the cognitive control of memory. Neuropsychologia, 45(13), 2883-2901. https://doi.org/10.1016/j.neuropsychologia.2007.06.015.

Becker, M., Sommer, T., \& Kühn, S. (2020). Inferior frontal gyrus involvement during search and solution in verbal creative problem solving: A parametric fMRI study. NeuroImage, 206, 116294. https://doi.org/10.1016/j.neuroimage.2019.116294. 
bioRxiv preprint doi: https:/doi.org/10.1101/2021.12.01.470605. this version posted December 2 2021. The copyright holder for this preprint (which was not certified by peer review) is the author/funder, who has granted bioRxiv a license to display the preprint in perpetuity. It is made available under aCC-BY-NC-ND 4.0 International license.

Behzadi, Y., Restom, K., Liau, J., \& Liu, T. T. (2007). A component based noise correction method (CompCor) for BOLD and perfusion based fMRI. NeuroImage, 37(1), 90101. https://doi.org/10.1016/j.neuroimage.2007.04.042.

Bodini, B., Cercignani, M., Khaleeli, Z., Miller, D. H., Ron, M., Penny, S., Thompson, A. J., \& Ciccarelli, O. (2013). Corpus callosum damage predicts disability progression and cognitive dysfunction in primary-progressive MS after five years. Human Brain Mapping, 34, 1163-1172. https://doi.org/10.1002/hbm.21499.

Borden, N. M. (2006). 3D angiographic atlas of neurovascular anatomy and pathology. Cambridge: Cambridge University Press.

Bozeat, S., Lambon Ralph, M. A., Patterson, K., Garrard, P., \& Hodges, J. R. (2000). Nonverbal semantic impairment in semantic dementia. Neuropsychologia, 9, 1207-1215. https://doi.org/10.1016/s0028-3932(00)00034-8.

Buckner, R. L. (2013). The cerebellum and cognitive function: 25 years of insight from anatomy and neuroimaging. Neuron, 80(3), 807-815. https://doi.org/10.1016/j.neuron.2013.10.044.

Burgess, P. W., \& Shallice, T. (1997). The Hayling and Brixton Tests. Bury St Edmunds: Thames Valley Test Company.

Camilleri, J. A., Müller, V. I., Fox, P., Laird, A. R., Hoffstaedter, F., \& Kalenscher, T. (2018). Definition and characterization of an extended multiple-demand network. NeuroImage, 165, 138-147. https://doi.org/10.1016/j.neuroimage.2017.10.020.

Chapman, C. A., Hasan, O., Schulz, P. E., \& Martin, R. C. (2020). Evaluating the distinction between semantic knowledge and semantic access: Evidence from semantic dementia 
and comprehension-impaired stroke aphasia. Psychonomic Bulletin \& Review, 27(4), 607-639. https://doi.org/10.3758/s13423-019-01706-6.

Cogdell-Brooke, L. S., Snowden, P. T., Violante, I. R., \& Thompson, H. E. (2020). A metaanalysis of functional magnetic resonance imaging studies of divergent thinking using activation likelihood estimation. Human Brain Mapping, 41(17), 5057-5077. https://doi.org/10.1002/hbm.25170.

Cohen, A. L., Ferguson, M. A., \& Fox, M. D. (2021). Lesion network mapping predicts poststroke behavioural deficits and improves localization. Brain, 144(4), 1-4. https://doi.org/10.1093/brain/awab002.

Conn, M. (2003). Neuroscience in medicine. Totowa, NJ: Humana Press.

Corbett, F., Jefferies, E., \& Lambon Ralph, M. A. (2011). Deregulated semantic cognition follows prefrontal and temporo-parietal damage: evidence from the impact of task constraint on nonverbal object use. Journal of Cognitive Neuroscience, 23(5), 11251135. https://doi.org/10.1162/jocn.2010.21539.

Coutanche, M. N., \& Thompson-Schill, S. L. (2015). Creating concepts from converging features in human cortex. Cerebral Cortex, 25(9), 2584-2593. https://doi.org/10.1093/cercor/bhu057.

Davey, J., Cornelissen, P. L., Thompson, H. E., Sonkusare, S., Hallam, G., Smallwood, J., \& Jefferies, E. (2015). Automatic and controlled semantic retrieval: TMS reveals distinct contributions of posterior middle temporal gyrus and angular gyrus. The Journal of Neuroscience, 35(46), 15230-15239. https://doi.org/10.1523/JNEUROSCI.4705-14.2015. 
Davey, J., Thompson, H. E., Hallam, G., Karapanagiotidis, T., Murphy, C., De Caso, I.,

Krieger-Redwood, K., Bernhardt, B. C., Smallwood, J., \& Jefferies, E. (2016).

Exploring the role of the posterior middle temporal gyrus in semantic cognition:

Integration of anterior temporal lobe with executive processes. NeuroImage, 137,

165-177. https://doi.org/10.1016/j.neuroimage.2016.05.051.

Del Gaizo, J., Fridriksson, J., Yourganov, G., Hillis, A. E., Hickok, G., Misic, B., Rorden, C., \& Bonilha, L. (2017). Mapping language networks using the structural and dynamic brain connectomes. ENEURO, 4(5), e0204-17.

\section{https://doi.org/10.1523/ENEURO.0204-17.2017.}

Dick, A. S., Garic, D., Graziano, P., \& Tremblay, P. (2019). The frontal aslant tract (FAT) and its role in speech, language and executive function. Cortex, 111, 148-163. https://doi.org/10.1016/j.cortex.2018.10.015.

Ding, J., Chen, K., Zhang, N., Luo, M., Du, X., Chen, Y., Yang, Q., Lv, Y., Zhang, Y., Song, L., Han, Z., \& Guo, Q. (2020). White matter networks dissociate semantic control from semantic knowledge representations: Evidence from voxel-based lesionsymptom mapping. Cognitive Neuropsychology, 37(7-8), 450-465. https://doi.org/10.1080/02643294.2020.1767560.

Duncan, J. (2010). The multiple-demand (MD) system of the primate brain: Mental programs for intelligent behaviour. Trends in Cognitive Science, 14(4), 172-179. https://doi.org/10.1016/j.tics.2010.01.004.

Fang, Y., Wang, X., Zhong, S., Song, L., Han, Z., Gong, G., \& Bi, Y. (2018). Semantic representation in the white matter pathway. PLOS Biology, 16(4), e2003993. https://doi.org/10.1371/journal. pbio.2003993. 
Fedorenko, E., Duncan, J., \& Kanwisher, N. (2013). Broad domain generality in focal regions of frontal and parietal cortex. PNAS, 110(41), 16616-16621. https://doi.org/10.1073/pnas.1315235110.

Ferguson, M. A., Lim, C., Cooke, D., Darby, R. R., Wu, O., Rost, N. S., Corbetta, M., Grafman, J., \& Fox, M. D. (2019). A human memory circuit derived from brain lesions causing amnesia. Nature Communications, 10, 3497. https://doi.org/10.1038/s41467-019-11353-Z.

Fornito, A., Zalesky, A., \& Breakspear, M. (2015). The connectomics of brain disorders. Nature Reviews Neuroscience, 16, 159-172. https://doi.org/10.1038/nrn3901.

Foulon, C., Cerliani, L., Kinkingnéhun, S., Levy, R., Rosso, C., Urbanski, M., Volle, E., \& Thiebaut de Schotten, M. (2018). Advanced lesion symptom mapping analyses and implementation as BCBtoolkit. GigaScience, 7(3), 1-17. https://doi.org/10.1093/gigascience/giy004.

Gao, Z., Zheng, L., Chiou, R., Gouws, A., Krieger-Redwood, K., Wang, X., Varga, D., Lambon Ralph, M. A., Smallwood, J., \& Jefferies, E. (2021). Distinct and common neural coding of semantic and non-semantic control demands. NeuroImage, 236, 118230. https://doi.org/10.1016/j.neuroimage.2021.118230.

Garcea, F. E., Greene, C., Grafton, S. T., \& Buxbaum, L. J. (2020). Structural disconnection of the tool use network after left hemisphere stroke predicts limb apraxia severity. Cerebral Cortex Communications, 1(1), tgaa035. https://doi.org/10.1093/texcom/tgaa035.

Gazzaniga, M. S. (2005). Forty-five years of split-brain research and still going strong. Nature Reviews Neuroscience, 6, 653-659. https://doi.org/10.1038/nrn1723. 
bioRxiv preprint doi: https:/doi.org/10.1101/2021.12.01.470605 this version posted December 2 2021. The copyright holder for this preprint (which was not certified by peer review) is the author/funder, who has granted bioRxiv a license to display the preprint in perpetuity. It is made available under aCC-BY-NC-ND 4.0 International license.

Gonzalez Alam, T. R. D. J., Karapanagiotidis, T., Smallwood, J., \& Jefferies, E. (2019).

Degrees of lateralisation in semantic cognition: Evidence from intrinsic connectivity. NeuroImage, 202, 116089. https://doi.org/10.1016/j.neuroimage.2019.116089.

Gonzalez Alam, T. R. D. J., McKeown, B. L. A., Gao, Z., Bernhardt, B., Vos de Wael, R., Margulies, D. S., Smallwood, J., \& Jefferies, E. (2021). A tale of two gradients: differences between the left and right hemispheres predict semantic cognition. Brain Structure and Function. https://doi.org/10.1007/s00429-021-02374-w.

Gonzalez Alam, T., Murphy, C., Smallwood, J., \& Jefferies, E. (2018). Meaningful inhibition: Exploring the role of meaning and modality in response inhibition. NeuroImage, 181, 108-119. https://doi.org/10.1016/j.neuroimage.2018.06.074.

Halai, A. D., Woollams, A. M., \& Lambon Ralph, M. A. (2020). Investigating the effect of changing parameters when building prediction models for post-stroke aphasia. Nature Human Behaviour, 4, 725-735. https://doi.org/10.1038/s41562-020-0854-5.

Hallam, G. P., Thompson, H. E., Hymers, M., Millman, R. E., Rodd, J. M., Lambon Ralph, M. A., Smallwood, J., \& Jefferies, E. (2018). Task-based and resting-state fMRI reveal compensatory network changes following damage to left inferior frontal gyrus. Cortex, 99, 150-165. https://doi.org/10.1016/j.cortex.2017.10.004.

Hallam, G. P., Whitney, C., Hymers, M., Gouws, A. D., \& Jefferies, E. (2016). Charting the effects of TMS with fMRI: Modulation of cortical recruitment within the distributed network supporting semantic control. Neuropsychologia, 93, 40-52. https://doi.org/10.1016/j.neuropsychologia.2016.09.012.

Han, Z., Ma, Y., Gong, G., He, Y., Caramazza, A., \& Bi, Y. (2013). White matter structural connectivity underlying semantic processing: evidence from brain damaged patients. Brain, 136, 2952-2965. https://doi.org/10.1093/brain/awt205. 
Head, H. (1926). Aphasia and kindred disorders of speech (Vol. II). New York: Cambridge University Press.

Hodgson, V. J., Lambon Ralph, M. A., \& Jackson, R. L. (2021). Multiple dimensions underlying the functional organization of the language network. NeuroImage, 241, 118444. https://doi.org/10.1016/j.neuroimage.2021.118444.

Hope, T. M. H., Leff, A. P., \& Price, C. J. (2018). Predicting language outcomes after stroke: Is structural disconnection a useful predictor? NeuroImage: Clinical, 19, 22-29. https://doi.org/10.1016/j.nicl.2018.03.037.

Huang, X., Du, X., Song, H., Zhang, Q., Jia, J., Xiao, T., \& Wu, J. (2015). Cognitive impairments associated with corpus callosum infarction: A ten cases study. International Journal of Clinical and Experimental Medicine, 8(11), 21991-21998.

Jackson, R. L. (2021). The neural correlates of semantic control revisited. NeuroImage, 224, 117444. https://doi.org/10.1016/j.neuroimage.2020.117444.

Jefferies, E. (2013). The neural basis of semantic cognition: converging evidence from neuropsychology, neuroimaging and TMS. Cortex, 49, 611-625. https://doi.org/10.1016/j.cortex.2012.10.008.

Jefferies, E., \& Lambon Ralph, M. A. (2006). Semantic impairment in stroke aphasia versus semantic dementia: a case-series comparison. Brain, 129, 2132-2147. https://doi.org/10.1093/brain/awl153.

Jefferies, E., Patterson, K., \& Lambon Ralph, M. A. (2008). Deficits of knowledge versus executive control in semantic cognition: Insights from cued naming. Neuropsychologia, 46, 649-658. https://doi.org/10.1016/j.neuropsychologia.2007.09.007. 
Jefferies, E., Thompson, H., Cornelissen, P., \& Smallwood, J. (2019). The neurocognitive basis of knowledge about object identity and events: dissociations reflect opposing effects of semantic coherence and control. Philosophical Transactions of the Royal Society B, 375, 20190300. https://doi.org/10.1098/rstb.2019.0300.

Johnson, N. F., Gold, B. T., Brown, C. A., Anggelis, E. F., Bailey, A. L., Clasey, J. L., \& Powell, D. K. (2017). Endothelial function is associated with white matter microstructure and executive function in older adults. Frontiers in Aging Neuroscience, 9(255). https://doi.org/10.3389/fnagi.2017.00255.

Jokinen, H., Ryberg, C., Kalska, H., Ylikoski, R., Rostrup, E., Stegmann, M. B., Waldemar, G., Madureira, S., Ferro, J. M., van Straaten, E. C., Scheltens, P., Barkhof, F., Fazekas, F., Schmidt, R., Carlucci, G., Pantoni, L., Inzitari, D., Erkinjuntti, T., \& LADIS group. (2007). Corpus callosum atrophy is associated with mental slowing and executive deficits in subjects with age-related white matter hyperintensities: the LADIS Study. Journal of Neurology, Neurosurgery, and Psychiatry, 78(5), 491-496. https://doi.org/10.1136/jnnp.2006.096792.

Krieger-Redwood, K., Teige, C., Davey, J., Hymers, M., \& Jefferies, E. (2015). Conceptual control across modalities: graded specialisation for pictures and words in inferior frontal and posterior temporal cortex. Neuropsychologia, 76, 92-107. https://doi.org/10.1016/j.neuropsychologia.2015.02.030.

Kristinsson, S., Zhang, W., Rorden, C., Newman-Norlund, R., Basilakos, A., Bonilha, L., Yourganov, G., Xiao, F., Hillis, A., \& Fridriksson, J. (2021). Machine learning-based multimodal prediction of language outcomes in chronic aphasia. Human Brain Mapping, 42(6), 1682-1698. https://doi.org/10.1002/hbm.25321. 
bioRxiv preprint doi: https:/doi.org/10.1101/2021.12.01.470605 this version posted December 2 2021. The copyright holder for this preprint (which was not certified by peer review) is the author/funder, who has granted bioRxiv a license to display the preprint in perpetuity. It is made available under aCC-BY-NC-ND 4.0 International license.

Kropf, E., Syan, S. K., Minuzzi, L., \& Frey, B. N. (2019). From anatomy to function: the role of the somatosensory cortex in emotional regulation. Brazilian Journal of Psychiatry, 41(3), 261-269. http://doi.org/10.1590/1516-4446-2018-0183.

Lambon Ralph, M. A., Jefferies, E., Patterson, K., \& Rogers, T. T. (2017). The neural and computational bases of semantic cognition. Nature Reviews Neuroscience, 18(1), 4255. https://doi.org/10.1038/nrn.2016.150.

Langen, C. D., Cremers, L. G. M., de Groot, M., White, T., Ikram, M. A., Niessen, W. J., \& Vernooij, M. W. (2018). Disconnection due to white matter hyperintensities is associated with lower cognitive scores. NeuroImage, 183, 745-756. https://doi.org/10.1016/j.neuroimage.2018.08.037.

Lanzoni, L., Thompson, H., Beintari, D., Berwick, K., Demnitz-King, H., Raspin, H., Taha, M., Stampacchia, S., Smallwood, J., \& Jefferies, E. (2019). Emotion and location cues bias conceptual retrieval in people with deficient semantic control. Neuropsychologia, 131, 294-305. https://doi.org/10.1016/j.neuropsychologia.2019.05.030.

Marcus, D. S., Fotenos, A. F., Csernansky, J. G., Morris, J. C., \& Buckner, R. L. (2010). Open access series of imaging studies: Longitudinal MRI data in nondemented and demented older adults. Journal of Cognitive Neuroscience, 22(12), 2677-2684. https://doi.org/10.1162/jocn.2009.21407.

Marino, J., Arias, J. C., \& Jefferies, E. (2020). Linking individual differences in semantic cognition to white matter microstructure. Neuropsychologia, 141, 107438. https://doi.org/10.1016/j.neuropsychologia.2020.107438.

Mummery, C. J., Patterson, K., Price, C. J., Ashburner, J., Frackowiak, R. S., \& Hodges, J. R. (2000). A voxel-based morphometry study of semantic dementia: relationship 
bioRxiv preprint doi: https:/doi.org/10.1101/2021.12.01.470605 this version posted December 2 2021. The copyright holder for this preprint (which was not certified by peer review) is the author/funder, who has granted bioRxiv a license to display the preprint in perpetuity. It is made available under aCC-BY-NC-ND 4.0 International license.

between temporal lobe atrophy and semantic memory. Annals of Neurology, 47(1), 36-45. https://doi.org/10.1002/1531-8249(200001)47:1<36::AID-ANA8>3.0.CO;2-L.

Noonan, K. A, Jefferies, E., Corbett, F., \& Lambon Ralph, M. A. (2010). Elucidating the nature of deregulated semantic cognition in semantic aphasia: Evidence for the roles of prefrontal and temporo-parietal cortices. Journal of Cognitive Neuroscience, 22(7), 1597-1613. https://doi.org/10.1162/jocn.2009.21289.

Noonan, K. A., Jefferies, E., Visser, M., \& Lambon Ralph, M. A. (2013). Going beyond inferior prefrontal involvement in semantic control: evidence for the additional contribution of dorsal angular gyrus and posterior middle temporal cortex. Journal of Cognitive Neuroscience, 25(11), 1824-1850. https://doi.org/10.1162/jocn_a_00442.

Nugiel, T., Alm, K. H., \& Olson, I. R. (2016). Individual differences in white matter macrostructure predict semantic control. Cognitive, Affective, \& Behavioral Neuroscience, 16, 1003-1016. https://doi.org/10.3758/s13415-016-0448-X.

Padmanabhan, J. L., Cooke, D., Joutsa, J., Siddiqi, S. H., Ferguson, M., Darby, R. R., Soussand, L., Horn, A., Kim, N. Y., Voss, J. L., Naidech, A. M., Brodtmann, A., Egorova, N., Gozzi, S., Phan, T. G., Corbetta, M., Grafman, J., \& Fox, M. D. (2019). A human depression circuit derived from focal brain lesions. Biological Psychiatry, 86(10), 749-758. https://doi.org/10.1016/j.biopsych.2019.07.023.

Patterson, K., Nestor, P. J., \& Rogers, T. T. (2007). Where do you know what you know? The representation of semantic knowledge in the human brain. Nature Reviews Neuroscience, 8, 976-987. https://doi.org/10.1038/nrn2277.

Raven, J. (1962). Coloured progressive matrices sets A, AB, B. London: H.K. Lewis. 
Rice, G. E., Lambon Ralph, M. A., \& Hoffman, P. (2015). The Roles of left versus right anterior temporal lobes in conceptual knowledge: An ALE meta-analysis of 97 functional neuroimaging studies. Cerebral Cortex, 25(11), 4374-4391.

\section{https://doi.org/10.1093/cercor/bhv024.}

Rizio, A. A., \& Diaz, M. T. (2016). Language, aging, and cognition: Frontal aslant tract and superior longitudinal fasciculus contribute to working memory performance in older adults. Neuroreport, 27(9), 689-693.

\section{https://doi.org/10.1097/WNR.0000000000000597.}

Rogers, T. T., Cox, C. R., Lu, Q., Shimotake, A., Kikuchi, T., Kunieda, T., Miyamoto, S., Takahashi, R., Ikeda, A., Matsumoto, R., \& Lambon Ralph, M. A. (2021). Evidence for a deep, distributed and dynamic code for animacy in human ventral anterior temporal cortex. eLife, 10, e66276. https://doi.org/10.7554/eLife.66276.

Rogers, T. T., Patterson, K., Jefferies, E., \& Lambon Ralph, M. A. (2015). Disorders of representation and control in semantic cognition: Effects of familiarity, typicality, and specificity. Neuropsychologia, 76, 220-239.

\section{https://doi.org/10.1016/j.neuropsychologia.2015.04.015.}

Rojkova, K., Volle, E., Urbanski, M., Humbert, F., Dell'Acqua, F., \& Thiebaut de Schotten, M. (2016). Atlasing the frontal lobe connections and their variability due to age and education: a spherical deconvolution tractography study. Brain Structure and Function, 221(3), 1751-1766. https://doi.org/10.1007/s00429-015-1001-3.

Salvalaggio, A., De Filippo De Grazia, M., Zorzi, M., Thiebaut de Schotten, M., \& Corbetta, M. (2020). Post-stroke deficit prediction from lesion and indirect structural and functional disconnection. Brain, 143(7), 2173-2188. 
Schulte, T., \& Müller-Oehring, E. M. (2010). Contribution of callosal connections to the interhemispheric integration of visuomotor and cognitive processes. Neuropsychology Review, 20, 174-190. https://doi.org/10.1007/s11065-010-9130-1.

Sierpowska, J., Gabarrós, A., Fernández-Coello, A., Camins, À., Castañer., S., Juncadella., M., François., C., \& Rodríguez-Fornells, A. (2019). White-matter pathways and semantic processing: intrasurgical and lesion-symptom mapping evidence. NeuroImage: Clinical, 22, 101704. https://doi.org/10.1016/j.nicl.2019.101704.

Smith, S. M., \& Nichols, T. E. (2009). Threshold-free cluster enhancement: Addressing problems of smoothing, threshold dependence and localisation in cluster inference. NeuroImage, 44(1), 83-98. https://doi.org/10.1016/j.neuroimage.2008.03.061.

Souter, N. E., Lindquist, K. A., \& Jefferies, E. (2021). Impaired emotion perception and categorization in semantic aphasia. Neuropsychologia, 162, 108052. https://doi.org/10.1016/j.neuropsychologia.2021.108052.

Spitz, G., Maller, J. J., O’Sullivan, R., \& Ponsford, J. L. (2013). White matter integrity following traumatic brain injury: The association with severity of injury and cognitive functioning. Brain Topography, 26(4), 648-660. https://doi.org/10.1007/s10548-013$\underline{0283-0 .}$

Stampacchia, S., Thompson, H. E., Ball, E., Nathaniel, U., Hallam, G., Smallwood, J., Lambon Ralph, M. A., \& Jefferies, E. (2018). Shared processes resolve competition within and between episodic and semantic memory: evidence from patients with LIFG lesions. Cortex, 108, 127-143. https://doi.org/10.1016/j.cortex.2018.07.007.

Stoodley, C. J., \& Schmahmann, J. D. (2009). Functional topography in the human cerebellum: A meta-analysis of neuroimaging studies. NeuroImage, 44(2), 489-501. https://doi.org/10.1016/j.neuroimage.2008.08.039. 
Thiebaut de Schotten, M., Dell'Acqua, F., Forkel, S. J., Simmons, A., Vergani, F., Murphy, D. G., \& Catani, M. (2011). A lateralized brain network for visuospatial attention. Nature Neuroscience, 14(10), 1245-1246. https://doi.org/10.1038/nn.2905.

Thiebaut de Schotten, M., Dell'Acqua, F., Ratiu, P., Leslie, A., Howells, H., Cabanis, E., IbaZizen, M. T., Plaisant, O., Simmons, A., Dronkers, N. F., Corkin, S., \& Catani, M. (2015). From Phineas Gage and Monsieur Leborgne to H.M.: Revisiting disconnection syndromes. Cerebral Cortex, 25(12), 4812-4827.

\section{https://doi.org/10.1093/cercor/bhv173.}

Thiebaut de Schotten, M., Foulon, C., \& Nachev, P. (2020). Brain disconnections link structural connectivity with function and behaviour. Nature Communications, 11, 5094. https://doi.org/10.1038/s41467-020-18920-9.

Thiebaut de Schotten, M., Tomaiuolo, F., Aiello, M., Merola, S., Silvetti, M., Lecce, F., Bartolomeo, P., Doricchi, F. (2014). Damage to white matter pathways in subacute and chronic spatial neglect: A group study and 2 single-case studies with complete virtual "in vivo" tractography dissection. Cerebral Cortex, 24(3), 691-706. https://doi.org/10.1093/cercor/bhs351.

Thompson, H. E., Almaghyuli, A., Noonan, K. A., barak, O., Lambon Ralph, M. A., \& Jefferies, E. (2018). The contribution of executive control to semantic cognition: Convergent evidence from semantic aphasia and executive dysfunction. Journal of Neuropsychology, 12, 312-340. https://doi.org/10.1111/jnp.12142.

van den Berg, E., Nys, G. M. S., Brands, A. M. A., Ruis, C., van Zandvoort, M. J. E., \& Kessels, R. P. C. (2009). The Brixton Spatial Anticipation Test as a test for executive function: Validity in patient groups and norms for older adults. Journal of the 
bioRxiv preprint doi: https:/doi.org/10.1101/2021.12.01.470605 this version posted December 2 2021. The copyright holder for this preprint (which was not certified by peer review) is the author/funder, who has granted bioRxiv a license to display the preprint in perpetuity. It is made available under aCC-BY-NC-ND 4.0 International license.

International Neuropsychological Society, 15, 695-703.

https://doi.org/10.1017/S1355617709990269.

Voineskos, A. N., Rajji, T. K., Lobaugh, N. J., Miranda, D., Shenton, M. E., Kennedy, J. L., Pollock, B. G., \& Mulsant, B. H. (2012). Age-related decline in white matter tract integrity and cognitive performance: A DTI tractography and structural equation modeling study. Neurobiology of Aging, 33, 21-34.

https://doi.org/10.1016/j.neurobiolaging.2010.02.009.

Wang, R., Benner, T., Sorensen, A. G., \& Wedeen, V. J. (2007). Diffusion toolkit: A software package for diffusion imaging data processing and tractography. Proceedings of the International Society for Magnetic Resonance in Medicine, 15, 3720.

Wang, X., Bernhardt, B. C., Karapanagiotidis, T., De Caso, I., Gonzalez Alam, T. R. D. J., Cotter, Z., Smallwood, J., \& Jefferies, E. (2018). The structural basis of semantic control: Evidence from individual differences in cortical thickness. NeuroImage, 181, 480-489. https://doi.org/10.1016/j.neuroimage.2018.07.044.

Wang, X., Gao, Z., Smallwood, J., \& Jefferies, E. (2021). Both default and multiple-demand regions represent semantic goal information. Journal of Neuroscience, 41(16), 36793691. https://doi.org/10.1523/JNEUROSCI.1782-20.2021.

Wang, X., Margulies, D. S., Smallwood, J., \& Jefferies, E. (2020). A gradient from long-term memory to novel cognition: Transitions through default mode and executive cortex. NeuroImage, 220, 117074. https://doi.org/10.1016/j.neuroimage.2020.117074.

Whitfield-Gabrieli, S., \& Nieto-Castanon, A. (2012). Conn: A functional connectivity toolbox for correlated and anticorrelated brain networks. Brain Connectivity, 2(3), 125-141. https://doi.org/10.1089/brain.2012.0073. 
Whitney, C., Kirk, M., O’Sullivan, J., Lambon Ralph, M. A., \& Jefferies, E. (2011). The neural organization of semantic control: TMS evidence for a distributed network in left inferior frontal and posterior middle temporal gyrus. Cerebral Cortex, 21, 10661075. https://doi.org/10.1093/cercor/bhq180.

Winkler, A. M., Ridgway, G. R., Webster, M. A., Smith, S. M., \& Nichols, T. E. (2014). Permutation inference for the general linear model. NeuroImage, 92, 381397. https://doi.org/10.1016/j.neuroimage.2014.01.060.

Wu, Y., Wang, J., Zhang, Y., Zheng, D., Zhang, J., Rong, M., Wu, H., Wang, Y., Zhou, K., \& Jiang, T. (2016). The neuroanatomical basis for posterior superior parietal lobule control lateralization of visuospatial attention. Frontiers in Neuroanatomy, 10, 32. https://doi.org/10.3389/fnana.2016.00032.

Yarkoni, T., Poldrack, R., Nichols, T., Van Essen, D. C., \& Wager, T. D. (2011). Large-scale automated synthesis of human functional neuroimaging data. Nature Methods, 8(8), 665-670. https://doi.org/10.1038/nmeth.1635.

Yeo, B. T. T., Krienen, F. M., Sepulcre, J., Sabuncu, M. R., Lashkari, D., Hollinshead, M., Roffman, J. L., Smoller, J. W., Zöllei, L., Polimeni, J. R., Fischl, B., Liu, H., Buckner, R. L. (2011). The organization of the human cerebral cortex estimated by intrinsic functional connectivity. Journal of Neurophysiology, 106(3), 1125-1165. https://doi.org/10.1152/jn.00338.2011.

Zhang, M., Varga, D., Wang, X., Krieger-Redwood, K., Gouws, A., Smallwood, J., \& Jefferies, E. (2021). Knowing what you need to know in advance: The neural processes underpinning flexible semantic retrieval of thematic and taxonomic relations. NeuroImage, 224, 117405. 


\section{Statements \& Declarations}

\section{Funding}

EJ was funded by a European Research Council Consolidator grant (FLEXSEM 771863). MTS was also funded by European Research Council Consolidator grant (DISCONNECTOME, Grant agreement No. 818521). AH was funded by the Rosetrees Trust (A1699) and European Research Council (GAP: 670428 - BRAIN2MIND_NEUROCOMP to MLR).

\section{Competing Interests}

The authors have no relevant financial or non-financial interests to disclose.

\section{Author Contributions (CRediT authorship contribution statement)}

Nicholas E. Souter: Conceptualization, Methodology, Formal analysis, Investigation, Data Curation, Writing - Original Draft, Writing - Review \& Editing, Visualization, Project administration. Xiuyi Wang: Formal analysis, Writing - Review \& Editing. Hannah Thompson: Investigation, Resources, Writing - Review \& Editing. Katya KriegerRedwood: Formal analysis, Writing - Review \& Editing. Michel Thiebaut de Schotten: Conceptualization, Methodology, Software, Formal analysis, Resources, Writing - Review \& Editing. Ajay D. Halai: Resources, Writing - Review \& Editing. Matthew A. Lambon

Ralph: Resources, Writing - Review \& Editing. Elizabeth Jefferies: Conceptualization, Methodology, Investigation, Writing - Review \& Editing, Supervision, Funding Acquisition.

\section{Data Availability}

Data for this project are available on the Open Science Framework (https://osf.io/6psqj/). Unthresholded group-level NIFTI files corresponding to the results presented here can be seen on Neurovault (https://neurovault.org/collections/10333/). Raw neuroimaging data for individual patients is not published here due to insufficient consent.

\section{Ethics approval}

This study was performed in line with the principles of the Declaration of Helsinki. Approval was granted by the York Neuroimaging Centre at the University of York (date: 24/10/2019, project ID: P1363).

\section{Consent to participate}

Informed consent was obtained from all individual participants included in the study. 
bioRxiv preprint doi: https://doi.org/10.1101/2021.12.01.470605; this version posted December 2, 2021. The copyright holder for this preprint (which was not certified by peer review) is the author/funder, who has granted bioRxiv a license to display the preprint in perpetuity. It is made available under aCC-BY-NC-ND 4.0 International license.

\section{Consent to publish}

The authors affirm that human research participants provided informed consent for publication of all data included within this manuscript, supplementary materials, and open data repositories. 
bioRxiv preprint doi: https://doi org/10.1101/2021.12.01.470605; this version posted December 2, 2021. The copyright holder for this preprint (which was not certified by peer review) is the author/funder, who has granted bioRxiv a license to display the preprint in perpetuity. It is made available under aCC-BY-NC-ND 4.0 International license.

$\underline{\text { Supplementary Materials Descriptive Captions }}$

\author{
Supplementary Figure 1
}

DESCRIPTIVE CAPTION FOR TEXT-TO-SPEECH: Supplementary Figure 1a reflects the mean percentage functionally disconnected for each network of interest. This peaks in the semantic control network at $85 \%$, followed by areas shared between the multiple demand and semantic control networks at $81 \%$, core semantic regions at $80 \%$, regions exclusive to the multiple demand network both at $75 \%$, and the default mode network at $44 \%$. Locations of most frequent damage are displayed for each network in following sections. Supplementary Figure 1b presents the default mode network, functional disconnection peaks in the left planum temporale, supramarginal gyrus, and bilateral superior temporal gyrus, and right temporal pole. Supplementary Figure 1c presents core semantic regions, functional disconnection peaks in the left temporal pole, superior temporal gyrus, temporo-occipital part of the middle temporal gyrus, angular gyrus and supramarginal gyrus. Supplementary Figure 1d presents the semantic control network, functional disconnection peaks in the left supramarginal gyrus and temporo-occipital part of the middle temporal gyrus. Supplementary Figure 1e presents regions shared by the semantic control and multiple demand networks, functional disconnection peaks in the left inferior frontal gyrus, precentral gyrus, and temporo-occipital part of the middle temporal gyrus. Supplementary Figure if presents the multiple demand network, functional disconnection peaks in the bilateral precentral gyrus and left postcentral gyrus.

\title{
Supplementary Figure 2
}

DESCRIPTIVE CAPTION FOR TEXT-TO-SPEECH: Supplementary Figure 2 presents clusters identified in symptom mapping as associated with relatively better performance. This is done for both the semantic composite score and Brixton Spatial Anticipation Test, for the measures of lesion, structural disconnection, and functional disconnection. Lesioned clusters associated with better semantic cognition are left fronto-parietal, and implicate the precentral, postcentral, and superior frontal gyri. Lesioned clusters associated with better Brixton performance include the frontal pole, planum temporale, angular gyrus, and postcentral gyrus. Structurally disconnected clusters associated with better semantic cognition include a small bilateral group of voxels in the parietal cortex which do not implicate specific regions or tracts, as well as a cluster in the left Heschl's gyrus. Structurally disconnected clusters associated with better Brixton performance are similarly sparse, but implicate the putamen, occipital pole, superior parietal lobule and precentral gyrus. Functionally disconnected clusters associated with better semantic cognition include one very cluster in the left cerebellum. No clusters met the threshold of $\mathbf{t}>\mathbf{2 . 6}$ for functionally disconnected clusters associated with better Brixton performance.

Supplementary Figure 3

DESCRIPTIVE CAPTION FOR TEXT-TO-SPEECH: Supplementary Figure 3 presents unthresholded overlap maps for the measures of lesion, structural disconnection, and functional disconnection. Supplementary Figure 3a presents lesion overlap. Lesions are confined to the left hemisphere and subsume much of the cortex, affecting each lobe, peaking in the precentral and middle frontal gyri. Maximum overlap is 16 cases. Supplementary Figure 3b presents structural disconnection overlap. Structural disconnection is largely left lateralised but with some spreading to the right hemisphere. Most left hemisphere white matter is implicated here, but this peaks in the left superior longitudinal fasciculus and inferior fronto-occipital fasciculus. 
bioRxiv preprint doi: https://doi org/10.1101/2021.12 01.470605; this version posted December 2, 2021. The copyright holder for this preprint (which was not certified by peer review) is the author/funder, who has granted bioRxiv a license to display the preprint in perpetuity. It is made available under aCC-BY-NC-ND 4.0 International license.

Maximum overlap is all 23 cases. Supplementary Figure 3c presents functional disconnection overlap. Functional disconnection is bilateral and extensive, subsuming almost the entirety of the brain. This disconnection peaks in the precentral and postcentral gyri. Maximum overlap is all 23 cases.

\section{Supplementary Figure 4}

DESCRIPTIVE CAPTION FOR TEXT-TO-SPEECH: Supplementary Figure 4a provides the mean probability that each tract of interest, as listed in section 2.5. of the manuscript, is disconnected across the sample. The mean probability of disconnection is highest in the corpus callosum at .99, followed by the superior longitudinal fasciculus 2 at .96 , the arcuate fasciculus long at .95 , and the superior longitudinal fasciculus 3 at .94 . The lowest probability of disconnection is in the uncinate fasciculus at .61. Supplementary Figure 4b provides the mean estimated proportion disconnected for each tract. This is highest in the frontal inferior longitudinal fasciculus at .37 , followed by the superior longitudinal fasciculus 3 at .32 , and the anterior arcuate fasciculus at $\mathbf{. 3 0}$. The lowest estimated mean proportion disconnected is in the corpus callosum, at $\mathbf{. 0 5}$. Supplementary Figure $4 \mathrm{c}$ displays a visualisation of the structural disconnection overlap map for the sample, thresholded at 19 cases. Structural disconnection is left lateralised at this threshold and shows maximal overlap with the superior longitudinal fasciculus and inferior fronto-occipital fasciculus. Supplementary Figure 4d through Supplementary Figure 4k display visualisations of, respectively, the anterior thalamic radiation, uncinate fasciculus, inferior longitudinal fasciculus, frontal aslant tract, arcuate fasciculus, superior longitudinal fasciculus, inferior fronto-occipital fasciculus, and corpus callosum. 